\title{
Transcriptional responses to temperature and low oxygen stress in Atlantic salmon studied with next-generation sequencing technology
}

\author{
Pål A Olsvik ${ }^{1 *}$, Vibeke Vikeså ${ }^{1,2}$, Kai K Lie ${ }^{1}$ and Ernst M Hevrøy ${ }^{1}$
}

\begin{abstract}
Background: Warmer seawater as a result of climate change may impose environmental challenges for Atlantic salmon aquaculture in its southernmost geographic range. Seawater temperatures above optimal level for growth may be reached in the warmest summer weeks. Caged fish can experience temperature and low oxygen saturation stress during such episodes, raising fish welfare and productivity concerns. In this work we compare the transcriptional responses in Atlantic salmon exposed to chronic high temperature $\left(19^{\circ} \mathrm{C}\right)$ and low oxygen saturation (4-5 mg/L) stress.
\end{abstract}

Results: We used next-generation sequencing and RT-qPCR to screen for effects, and focused on growth regulation and oxidative stress in fish exposed to sub-optimal conditions. Both prolonged temperature (45 days) and low oxygen (120 days) stress had a significant negative effect on growth. The main effect of heat stress appears to be a general reduced transcriptional rate in salmon liver, while mechanisms typically associated with responses induced by chemical drugs were stimulated. Heat stress significantly down-regulated several transcripts encoding proteins involved in the protection against oxidative stress, including CUZn SOD, Mn SOD, GPX1 and GR, as well as additional stress markers HIF1A, CYP1A, MTOR and PSMC2 (RT-qPCR data). In salmon held at low oxygen concentration for four months protein ubiquitination (protein catabolism) was the most strongly affected pathway. According to the RT-GPCR data, low oxygen stress significantly up-regulated the transcriptional levels of IGFBP1B and down-regulated the levels of GR. Pathway analysis suggests that high temperature and low oxygen saturation stress affects many similar mechanisms in Atlantic salmon. Based on the gene lists, six out of the top ten predicted upstream transcriptional regulators, 1,2-dithiol-3-thione sirolimus, CD437, 5-fluorouracil, HNF4A and NFE2L2, were similar between the two treatments.

Conclusions: In conclusion, temperature and low oxygen saturation stress affect many identical mechanisms in liver cells resulting in a metabolic depression, but these effects are not necessarily mediated through altered transcription of the same genes.

Keywords: Farmed salmon, Climate change, Temperature and hypoxia stress, Next-generation sequencing

\section{Background}

Climate change may introduce several environmental challenges for farmed fish caged in seawater pens. In temperate areas, increased seawater temperature during the summer months may represent a problem for farmed fish unable to swim to colder water. Ectothermic animals such as fish normally show temperature-dependent oxygen

\footnotetext{
* Correspondence: pal.olsvik@nifes.no

${ }^{1}$ National Institute of Nutrition and Seafood Research, Nordnesboder 1-2,

N-5005 Bergen, Norway

Full list of author information is available at the end of the article
}

consumption [1]. Increasing temperatures may induce low oxygen stress since oxygen solubility is reduced in warmer water. Fish may also experience hypoxia at elevated temperatures even under conditions with unchanged oxygen tension, for example increased temperature could reduce the binding capacity of hemoglobin for oxygen transport $[2,3]$. Environmental temperature affects almost all aspects of fish physiology, and effects of temperature fluctuation on teleosts have been studied extensively for decades [4]. Sedentary fish species may be exposed to stressful shortterm temperature spikes during the summer months

\section{Biomed Central}


when ambient seawater temperature changes rapidly. Metabolism in ectothermic fish is highly dependent on environmental temperature [5], with suboptimal conditions affecting both feed intake and growth [6]. For instance, sea-caged Atlantic salmon (Salmo salar), unable to escape sudden temperature bursts by vertical migration, may experience considerable challenges with temperature adaptation. In southern Norwegian fjords such temperature periods lasting a few weeks have been recorded in recent years with observed temperatures above optimal levels for locally farmed Atlantic salmon [6], raising both fish welfare and productivity challenges.

Numerous studies have profiled global gene expression changes in fishes exposed to elevated temperature and hypoxia. Both acute and chronic heat stress can induce relative large transcriptional changes in salmonids $[2,4,7,8]$ and other fish species [3,9-11], including in coldadapted Antarctic fish [12,13]. Also hypothermia can induce transcriptional changes in fishes [14,15]. Depending on studied cell type, typical responses in fish exposed to heat stress include altered transcription in genes involved in protein processing, transcription and cell growth [9], protein folding and heat shock proteins $[2,8,10,11]$, cell cycle arrest and apoptosis, and proteolytic protein degradation [11], $\beta$-oxidation of fatty acids and peroxisome proliferator-activated receptor genes $[12,13]$, acute inflammatory response [12], and ribosomal genes and catabolism, i.e. metabolism [7,16]. Although oxidative stress response has been reported as one of the strongest affected mechanisms in fish exposed to acute temperature stress according to global genome screening [12], surprisingly few of these studies have reported large transcriptional changes in genes associated with the antioxidative defense.

As for temperature, hypoxia may have profound effect on biochemical, molecular and physiological processes in fish [17]. Consequences of low dissolved oxygen are often sublethal and affect growth, immune responses and reproduction [18]. For Atlantic salmon, oxygen levels falling below the critical point of $6 \mathrm{mg} / \mathrm{L}$ are considering hypoxic [19]. In one of the first microarray screening studies with fish, Gracey et al. [20] showed profound effects of hypoxia on the longjawed mudsucker (Gillichthys mirabilis) after 5 days of treatment. They observed effects on transcripts encoding proteins involved in protein synthesis and locomotion, as well as on genes needed for anaerobic ATP production. Studying gene expression changes in zebrafish (Danio rerio) embryos exposed to 24 hours of hypoxia during development, Ton et al. [21] identified transcriptional changes indicating metabolic depression with a switch from aerobic to anaerobic metabolism and energy preservation. More recent studies have shown changes in expression of genes related to physiological adaptation to low environmental oxygen in gills of zebrafish after 21 days of hypoxia exposure [22], effects on general metabolism, catabolism, and ubiquitin-proteasome pathway in brain, gill and liver of Japanese medaka (Oryzias latipes) after 56 days of exposure to hypoxia [23,24], responses in genes involved in metabolic energy changes in brain, gill and liver of Xiphophorus maculatus after 6 days of exposure to hypoxia [25], as well as activation of glycolysis and oxidative phosphorylation in fin tissue of Japanese medaka after 7 days of exposure to hypoxia [26]. In gonads of zebrafish acute hypoxia for 4 and 14 days affected responses such as metabolism of carbohydrate and proteins, and reactive oxygen species metabolism, while chronic hypoxia affected lipid metabolism, steroid hormones, and immune responses [27].

In this work we wanted to evaluate how Atlantic salmon cope with environmental challenges possibly imposed by climate change by comparing the molecular responses in fish held at sub-optimal temperature and oxygen levels. Recent findings suggest that thermal responses of fish can be oxygen-limited [28], indicating that oxygen-limited thermal tolerance is of major importance in the response of fish to climate change [29]. Global transcriptional responses in liver of adult Atlantic salmon exposed to high temperature $\left(19^{\circ} \mathrm{C}\right)$ and low oxygen (4-5 $\mathrm{mg} \mathrm{O}_{2} / \mathrm{L}$ ) was examined using next-generation sequencing technology. Tissue samples were obtained from two independent experiments. In the first experiment, described in detail by Hevrøy et al. [30], Atlantic salmon was held at $13^{\circ} \mathrm{C}$ (optimal temperature, control), $15^{\circ} \mathrm{C}, 17^{\circ} \mathrm{C}$ or $19^{\circ} \mathrm{C}$ (heat stressed). Effects of heat stress were evaluated by comparing the transcriptional patterns in the $13^{\circ} \mathrm{C}$ and $19^{\circ} \mathrm{C}$ groups of fish using suppression subtractive hybridization ( $\mathrm{SSH}$ ) cDNA libraries followed by FLX 454 sequencing. In the second experiment, control fish were held at optimal oxygen (7-8 mg/L) and low oxygen stressed fish held at sub-optimal oxygen (4-5 mg/L). Effects of low oxygen were evaluated by comparing the transcriptional patterns in the two groups of fish using normalized cDNA libraries followed by FLX 454 sequencing. In total we sequenced about 1.5 million reads from four cDNA libraries, and used gene ontology and pathway analysis tools to evaluate the responses. Real-time RTqPCR analysis was used on an extended number of fish for follow-up examination of relevant genes, including growth regulation and oxidative stress relevant genes.

\section{Results}

Temperature and low oxygen trials, growth

Somatic growth of Atlantic salmon, measured as thermal growth coefficient (TGC), significantly decreased with increasing exposure temperature (1-way ANOVA, Figure 1A). In salmon exposed to low dissolved oxygen saturation there was a significant reduction in TGC compared to fish 


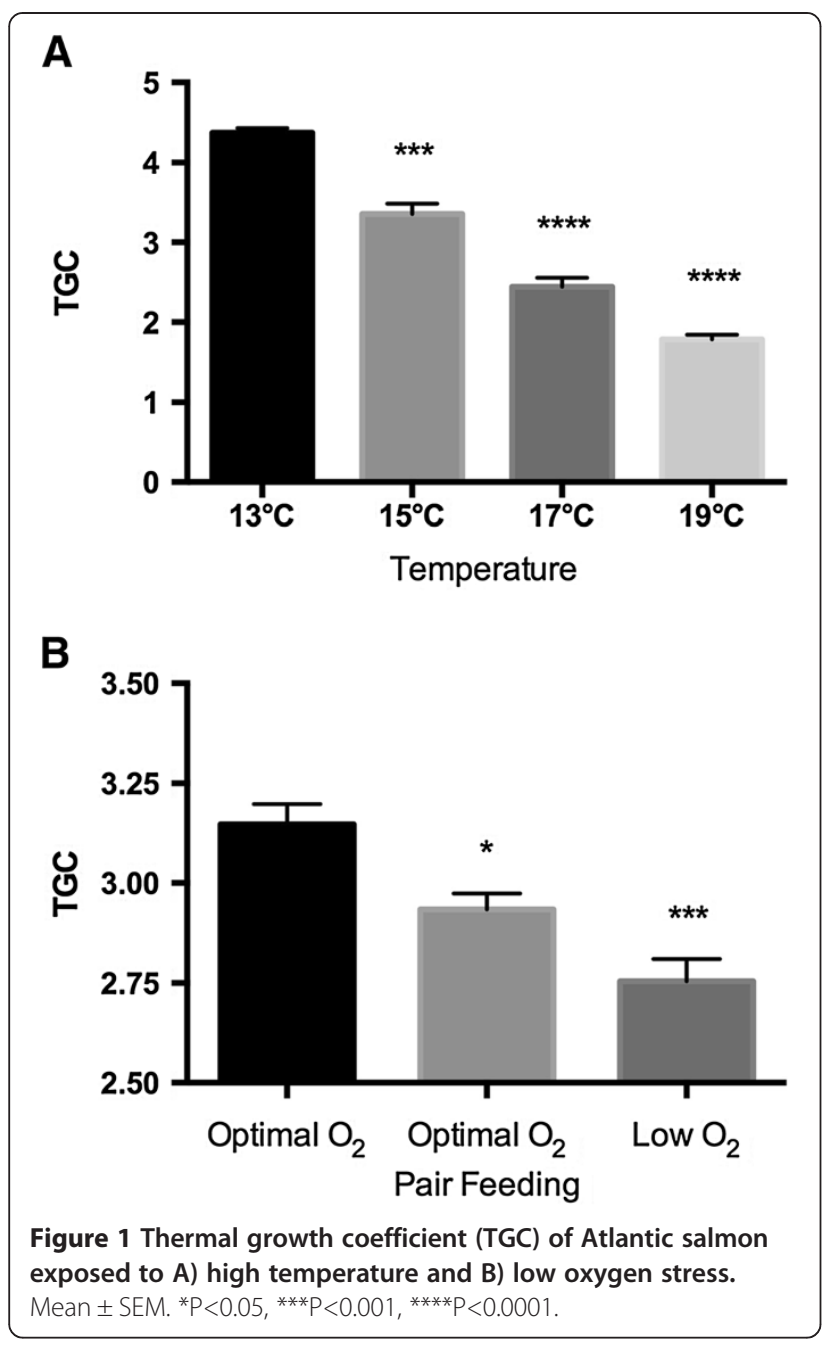

kept at normal oxygen saturation levels (1-way ANOVA, Figure 1B). Pair fed fish raised on normal oxygen saturation had reduced TGC compared to normal fed fish at kept at similar oxygen level, but higher growth than fish kept at low dissolved oxygen saturation (1-way ANOVA, Figure 1B). By comparing fish growth from these two studies, comparable TGC values ( $<3$, Figures $1 \mathrm{~A}$ and $1 \mathrm{~B})$ were observed in fish held at sub-optimal temperatures above $15^{\circ} \mathrm{C}$ with optimal oxygen, in pair fed fish kept at with optimal oxygen levels, and in fish exposed to low dissolved oxygen saturation.

\section{$454 \mathrm{FLX}$ sequencing and assembly}

Table 1 shows an overview of the 454 FLX sequencing data. In total, 1,425,167 reads were sequenced from the four cDNA libraries. A total of 773,725 sequence reads, with an average read length of 333 nucleotides, were obtained from the temperature stress experiment (forward and reverse SSH cDNA libraries), while 651,442 sequence reads with an average read length of 526 nucleotides were obtained from the low oxygen experiment (normal $\mathrm{O}_{2}$ and low $\mathrm{O}_{2}$ normalized cDNA libraries). The number of reads sequenced from the forward and reverse SSH cDNA libraries were 313713 and 427812 , respectively. The total number of reads sequenced from the normal oxygen cDNA library was 357347 , while 401270 reads were sequenced from the low oxygen cDNA library.

Assembly of sequenced reads from the SSH cDNA libraries was conducted with the GS De Novo Assembler 2.6 (Newbler software, build 20110523_1851). Using a minimum overlap length of 40 and minimum overlap identity of 90, 186508 reads (59.5\%) were assembled from the forward SSH cDNA library (up-regulated by $19^{\circ} \mathrm{C}$ ). The number of partially assembled reads from this library was 26831 , and the number of singletons was 37564 . The total number of contigs from the forward SSH cDNA library was 5 067. Of these, 1928 , with an average length of $664 \mathrm{bp}$, were large contigs $(>500 \mathrm{bp}$ ). From the reverse SSH cDNA library (down-regulated by $\left.19^{\circ} \mathrm{C}\right) 303804$ reads were assembled (71.0\%). 56730 reads from this library were partially assembled and the cDNA library contained 43432 singletons. The total number of contigs obtained from the reverse SSH cDNA library was 5 659, while the number of large contigs with a

Table 1 Summary of 454 sequencing data

\begin{tabular}{|c|c|c|c|c|}
\hline & \multicolumn{2}{|c|}{ Temperature } & \multicolumn{2}{|c|}{ Hypoxia } \\
\hline & $13^{\circ} \mathrm{C}(\mathrm{EH} 1)$ & $19^{\circ} \mathrm{C}(\mathrm{EH} 2)$ & Normal $\mathrm{O}_{2}$ & Low $\mathrm{O}_{2}$ \\
\hline Tissue & Liver & Liver & Liver & Liver \\
\hline Individuals & 6 & 6 & 9 & 9 \\
\hline Method & SSH library & SSH library & Normalized library & Normalized library \\
\hline Sequencing & FLX 454 GS-titanium & FLX 454 GS-titanium & FLX 454 GS-titanium & FLX 454 GS-titanium \\
\hline Platform & CEES, UiO & CEES, UiO & LGC Genomics, Munich & LGC Genomics, Munich \\
\hline Reads & 334403 & 439322 & 375347 & 401270 \\
\hline All contigs & 14325 & 5659 & 10827 & 11478 \\
\hline Large contigs & 2289 & 1790 & 7817 & 8498 \\
\hline IPA input $>50$ reads & 754 & 1229 & 1466 & 1591 \\
\hline
\end{tabular}


length of $>500$ bp was 1790 . These had an average length of $626 \mathrm{bp}$.

Using Newbler 2.6 (build 20110517_1502) with GSAssembler parameters with minimum overlap length of 40 and a minimum overlap identity of 90, 264 911 reads were assembled from the normal oxygen cDNA library. The number of partial assembled reads from this cDNA library was 26 667, while the number of singletons was 57 604. In total, 10827 contigs were obtained from the normal oxygen cDNA library, of which 7817 (>500 pb) with an average length of $1173 \mathrm{bp}$ were used for downstream analyses. From the low oxygen cDNA library, 283599 reads were assembled. From this cDNA library, the number of partially assembled reads was 28095 while the number of singletons was 58 462. The total number of contigs from this cDNA library was 11478 , of which 8498 were large contigs (>500 bp). Large contigs from the low oxygen cDNA library had an average size of $1191 \mathrm{bp}$.

\section{Annotation and gene ontology (GO) enrichment analysis}

To search for possible impurities in the cDNA pool, MEGAN software was used. Metatranscriptomic analysis showed that reads from all four cDNA libraries had very few hits against microbial and human sequences, and with a vast majority of hits against sequences from teleostean species, suggesting a very low level of contamination in the cDNA pools.

Of the 754 contigs consisting of more than 50 reads from the forward SSH cDNA library $\left(19^{\circ} \mathrm{C}\right.$ group), $58.0 \%$ were annotated with a Blastx cut-off of 10-6 (Additional file 1A). $28.1 \%$ of the contigs showed no Blastx hits against the GenBank database. From the reverse SSH cDNA library $\left(13^{\circ} \mathrm{C}\right.$ group), $51.7 \%$ of the 1229 contigs consisting of more than 50 reads were annotated with a Blastx cut-off of $10-6$ (Additional file 1B). $36.3 \%$ of the contigs from the reverse SSH cDNA library showed no Blastx hits. Similarity distribution showed most hits against Atlantic salmon sequences. Of the 1591 contigs consisting of more than 50 reads from the low oxygen stress normalized cDNA library (Additional file 2A), 85.8\% were annotated with a Blastx cut-off of 10-6. 7.5\% of the contigs showed no Blastx hits against the GenBank database. From the normal oxygen normalized cDNA library, $85.3 \%$ of the 1466 contigs consisting of more than 50 reads were annotated with a Blastx cut-off of 10-6 (Additional file 2B). $8.0 \%$ of the contigs from the normal oxygen normalized cDNA library showed no Blastx hits. Similarity distribution of the SSH cDNA contigs showed most hits against Atlantic salmon sequences, while similarity distribution of the normalized cDNA contigs showed most hits against zebrafish sequences, closely followed by Atlantic salmon sequences.
GO enrichment analysis was performed by using the Fisher's Exact Test, as implemented in the Blast2GO software, to study temperature- or low oxygen- specific responses in Atlantic salmon using contigs containing more than 50 reads. Figure 2 shows over- or under expressed GOs as determined by the Fisher's Exact Test $(\mathrm{P}<0.05)$. Figure 2A shows enriched GOs in Atlantic salmon exposed to $19^{\circ} \mathrm{C}$. Relative few GOs were differentially expressed in heat stressed fish at $19^{\circ} \mathrm{C}$ compared to fish kept at optimal temperature at $13^{\circ} \mathrm{C}$. Heat stress resulted in overexpression of GOs linked to oxygen binding and transporter activity, i.e. GO:0019825 oxygen binding and GO:000534 oxygen transporter activity. Figure 2B shows differentially expressed GOs in Atlantic salmon exposed to low oxygen saturation with significance levels of $\mathrm{P}<0.001$. Many GOs linked to general metabolism were significantly affected by low oxygen saturation, suggesting a compensatory response induced by low oxygen stress. Top listed overexpressed GOs were GO:0090304 nucleic acid metabolic process, GO:0016070 RNA metabolic process and GO:0031323 regulation of cellular metabolic process, whereas GOs linked to oxygen reduction reactions such as GO:0055114 oxidation-reduction process and GO:0016491 oxidoreductase activity were underexpressed. All significant over- or underexpressed GOs, including IDs and terms, P-values, and the number of transcripts associated with a specific GO term from the cDNA libraries, as determined by Fisher's Exact Test, are shown in Additional file 3. From the temperature stress experiment, enriched GOs are shown in the Additional file 3, worksheet A. Form the low oxygen experiment, we list GO enrichment analyses data both for contigs only consisting of more than 50 reads (>50 reads) (worksheet B) and by using all large contigs (worksheet C). According to the latter analysis, GOs linked to lipid metabolism were underexpressed in salmon held at low oxygen saturation, with GO:0006629 lipid metabolic process and GO:0006631 fatty acid metabolic process being most significant. In total, by also including contigs with less than 50 reads, fewer significant GOs were found (133 versus 266). The larger dataset however appears to provide more specific GOs than by using only contigs consisting of $>50$ reads.

\section{Functional analyses}

A gene list consisting of 1066 identifiers recognized by IPA from the temperature stress experiment was used for pathway analysis. The list was generated by considering all the genes in the forward SSH cDNA library as being up-regulated by temperature stress and given a foldchange score of 2 , and all the genes in the reverse $\mathrm{SSH}$ cDNA library as being down-regulated by temperature stress and given a fold-change score of -2. IPA analysis for temperature stress genes revealed seven top networks, "Protein Synthesis, Gene Expression, Cancer" (score 53) 


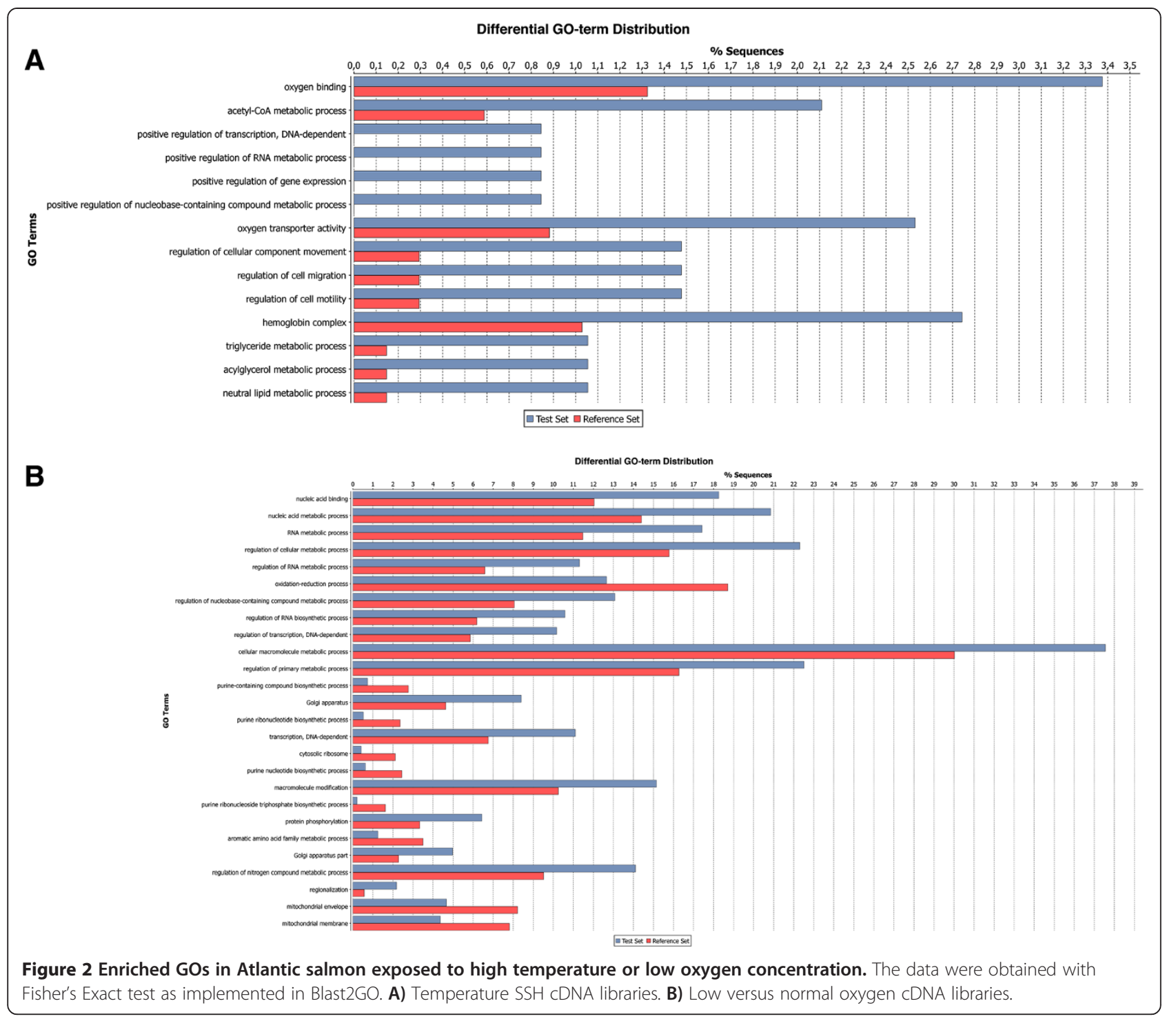

(Figure 3A), "RNA Post-Transcriptional Modification, Gene Expression, Protein Synthesis" (score 48), "DNA Replication, Recombination, and Repair, Energy Production, Nucleic Acid Metabolism" (score 37), "Hematological Disease, Metabolic Disease, Nutritional Disease" (score 36) (Figure 3B), "Gene Expression, Protein Synthesis, CellTo-Cell Signaling and Interaction" (score 36), "Drug Metabolism, Protein Synthesis, Glutathione Depletion In Liver" (score 30) (Figure 3C), and "Free Radical Scavenging, Lipid Metabolism, Molecular Transport" (rank 7, score 28) (Figure 3D). Top canonical pathways were "EIF2 Signaling" (P-value 1,03E-55, ratio 62/200 (0,31)), "Acute Phase Response Signaling" (P-value 1,11E-22, ratio 34/179 $(0,19))$, "Regulation of eIF4 and p70S6K Signaling" (P-value 5,74E-20, ratio 30/17 $5(0,171)$ ), “mTOR Signaling" (P-value 1,32E-17, ratio $31 / 211(0,147))$, and "Mitochondrial Dysfunction" (P-value 9,3E-17, ratio
28/186 (0,151)). IPA Upstream Regulator analytic aim to identify the cascade of upstream transcriptional regulators that can explain the observed gene expression changes in the dataset, and help illuminate the biological activities occurring in the tissues or cells being studied. IPA analysis suggested that "1,2-dithiol-3-thione" (P-value 6,49E-08), "sirolimus" (P-value 2,50E-07), "pirinixic acid" (P-value 2,80E-07), "CD 437" (P-value 3,64E-07), and "5-fluorouracil" (P-value 3,93E-06) to be the top upstream regulators. Additional file 4 shows the predicted upstream regulators of temperature stress in Atlantic salmon liver with an overlap P-value higher than 10E-05 (worksheet "Temperature"). IPA-Tox analysis generates a focused toxicity and safety assessment of chemical compounds using toxicogenomics approaches, but can also be used to assess molecular perturbation of all kinds of environmental stressors, i.e. temperature and low oxygen. From the temperature stress 


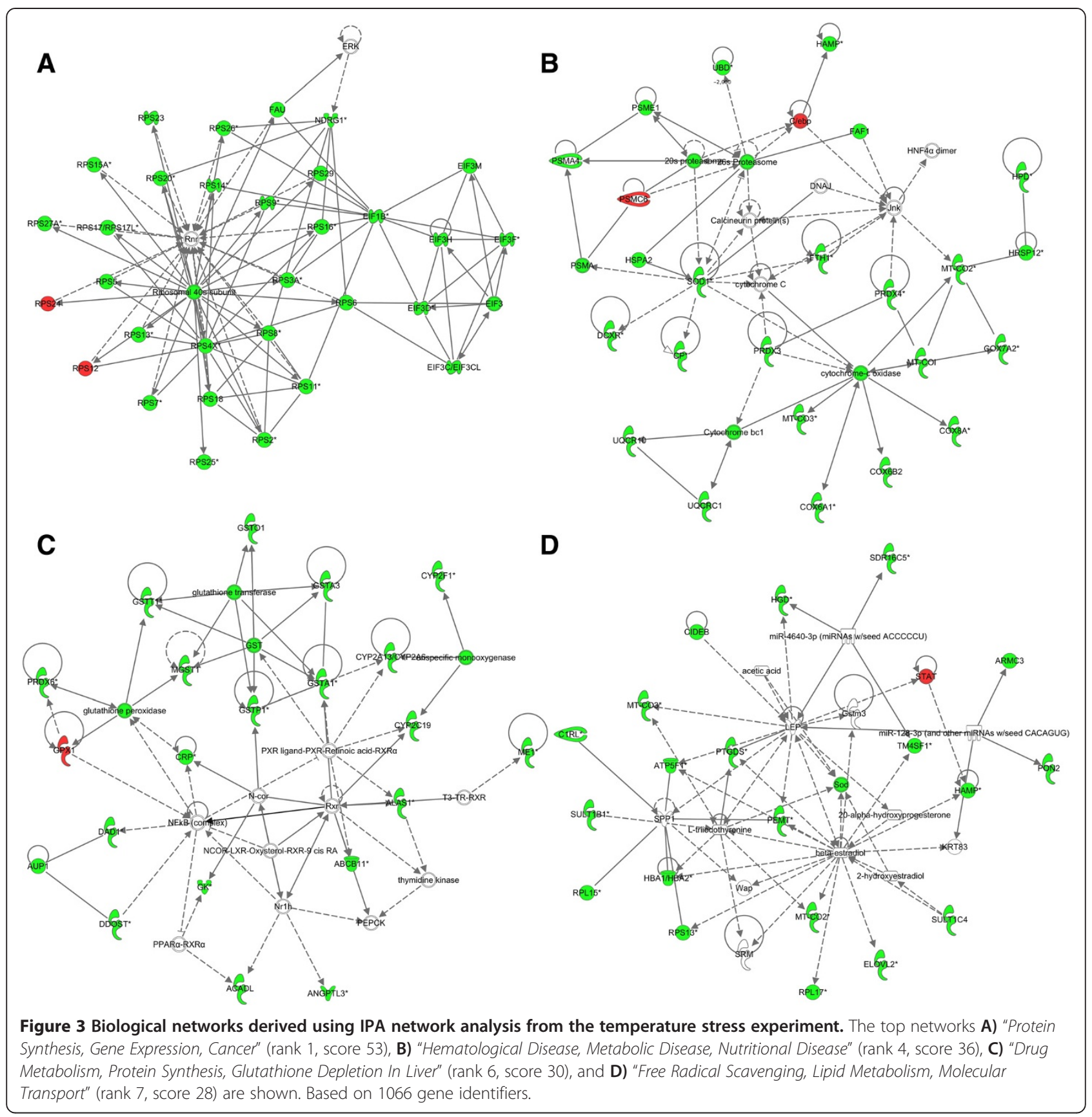

experiment IPA-Tox analysis listed "Mitochondrial Dysfunction" (P-value 4,96E-15, ratio 25/150 (0,167)), "Positive Acute Phase Response Proteins" (P-value 2,78E-14, ratio 13/30 (0,433)), "LXR/RXR Activation" (P-value 5,83E-14, ratio 22/124 $(0,177))$, "Negative Acute Phase Response Proteins" (P-value 6,33E-14, ratio 8/8 (1)) and "LPS/IL-1 Mediated Inhibition of RXR Function" (P-value 4,11E10 , ratio $25 / 247(0,101))$ as the top five most significant effects.

The IPA Compare function was used to find transcripts solely expressed in the low oxygen group and not in the normal oxygen group, creating a list consisting of 221 genes with positive IPA identifiers. According to the IPA Core analysis, the top three affected networks solely expressed in the low oxygen group were "Lipid Metabolism, Small Molecule Biochemistry, Dermatological Diseases and Conditions" (score 77), "Nucleic Acid Metabolism, Small Molecule Biochemistry, Organ Morphology" (score 33) and "Hereditary Disorder, Metabolic Disease, Cardiovascular Disease" (score 33). Figure 4 shows the second highest scored IPA Core Analysis network by using gene identifiers unique for the low oxygen group. This network, 


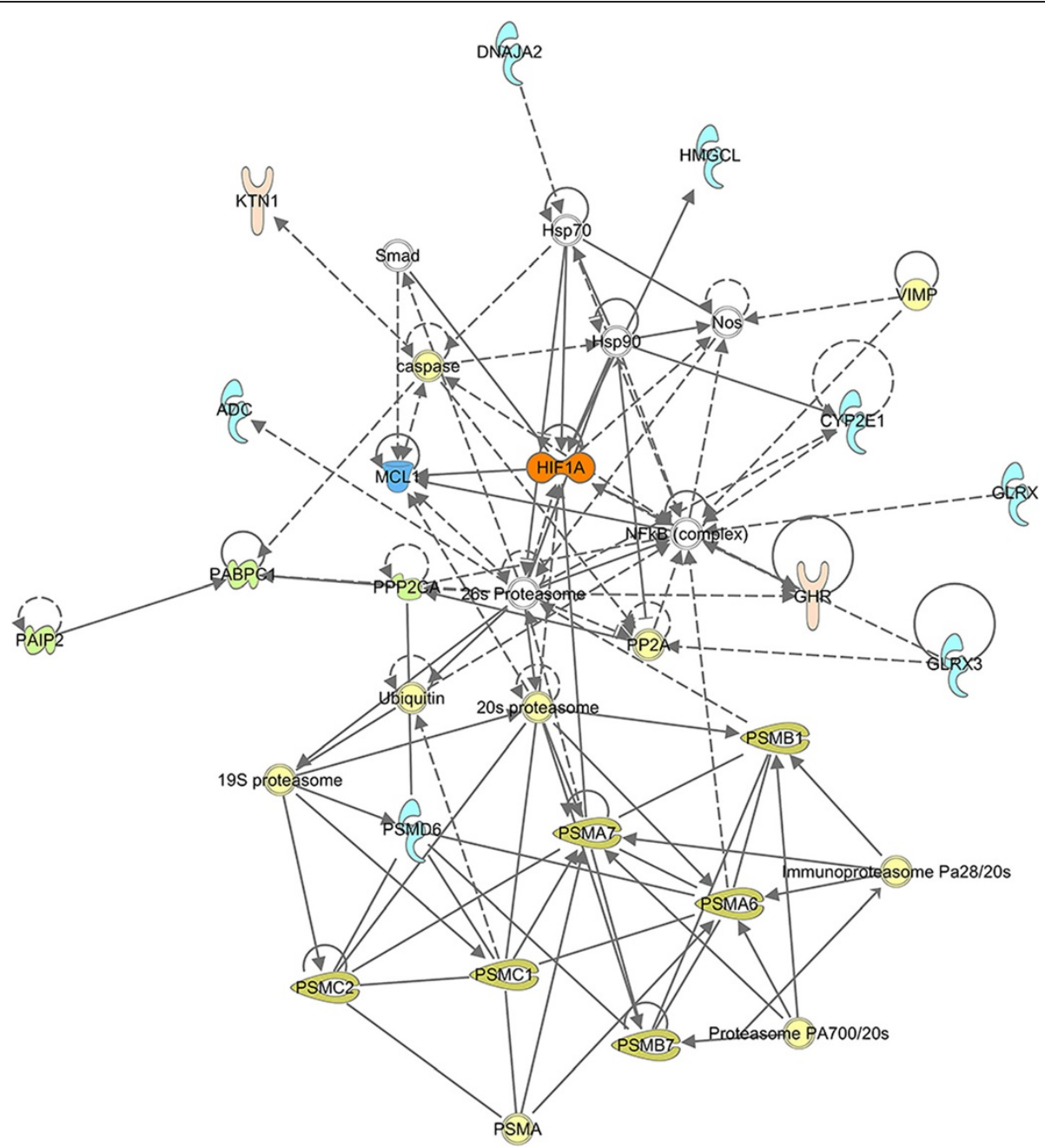

Figure 4 Biological network derived using IPA network analysis from the low oxygen stress experiment. The top network "Nucleic acid metabolism, small molecule biochemistry, organ morphology" (rank 1, score 33) is shown. Based on 221 gene identifiers.

"Nucleic acid metabolism, small molecule biochemistry, organ morphology", includes the hifla gene in a central position, suggesting a link to hypoxia. The top canonical pathway, "Protein Ubiquitination Pathway", had a P-value of $8,68 \mathrm{E}-05$ and a ratio of $11 / 268(0,041)$. According to the IPA Core analysis "1,2-dithiol-3-thione" (P-value 6,49E-08), "sirolimus" (P-value 2,50E-07), "pirinixic acid" (P-value 2,80E-07), "CD 437" (P-value 3,64E-07) and "5fluorouracil" (P-value 3,93E-06) were the top upstream regulators. Additional file 4 lists the predicted upstream regulators of low oxygen stress in Atlantic salmon liver with an overlap P-value higher than 10E-03 (worksheet "Hypoxia"). Activation z-scores from the low oxygen experiment were not possible to calculate since we did not have any fold-change input. Low oxygen exposure induced the following effects according to the IPA-Tox analysis, "Glutathione Depletion - Phase II Reactions" (P-value 1,11E-03, ratio 3/20 (0,15)), "Hypoxia-Inducible Factor Signaling" (P-value 6,08E-03, ratio 4/70 (0,057)), Cholesterol
Biosynthesis (P-value 1,17E-02, ratio 2/16 (0,125)), Cytochrome P450 Panel - Substrate is a Xenobiotic (Human) (P-value 1,64E-02, ratio 2/19 $(0,105))$ and Mitochondrial Dysfunction (P-value 2,03E-02, ratio 5/150 $(0,033)$ ).

To compare the degree of overlap in response to temperature and low oxygen stress and how these stressors differentially affect Atlantic salmon, the data were analyzed with the Venny tool [31]. Only 19 transcripts, listed in Table 2, were common for the two different stressors (Figure 5). In general, both treatments appear to have affected overall transcription and metabolism.

\section{RT-qPCR analyses}

From the temperatures stress experiment, transcriptional levels of 12 target genes were determined with RT-qPCR in liver of adult salmon from 36 individual fish kept at four different temperatures $\left(13^{\circ} \mathrm{C}, 15^{\circ} \mathrm{C}, 17^{\circ} \mathrm{C}\right.$ and $\left.19^{\circ} \mathrm{C}\right)$ for 45 days. Markers of oxidative stress (CuZn SOD, Mn SOD, CAT, GPx1 and GR), hypoxia (HIF1A), anti- 


\begin{tabular}{|c|c|c|c|c|}
\hline Gene symbol & Gene product & $\begin{array}{l}\text { Temperature } \\
\text { effect }\end{array}$ & Metabolic function & Protein function \\
\hline$\overline{A D K}$ & Adenosine kinase & Up & ATP/ITP metabolism & $\begin{array}{l}\text { ATP dependent phosphorylation of adenosine } \\
\text { and other related nucleoside analogs to } \\
\text { monophosphate derivatives }\end{array}$ \\
\hline BTD & Biotinidase & Up & Biotin metabolism & $\begin{array}{l}\text { Catalytic release of biotin from biocytin, the } \\
\text { product of biotin-dependent carboxylases } \\
\text { degradation }\end{array}$ \\
\hline CREB3L3 & $\begin{array}{l}\text { CAMP responsive element } \\
\text { binding protein } 3 \text {-like } 3\end{array}$ & Up & Transcription regulation & $\begin{array}{l}\text { Transcription factor that may act during } \\
\text { endoplasmic reticulum stress by activating } \\
\text { unfolded protein response target genes }\end{array}$ \\
\hline CYP1A & $\begin{array}{l}\text { Cytochrome P450, family } 1 \text {, } \\
\text { subfamily A }\end{array}$ & Up & Monooxygenase activity & $\begin{array}{l}\text { Oxidization of a variety of structurally unrelated } \\
\text { compounds, including steroids, fatty acids, } \\
\text { and xenobiotics }\end{array}$ \\
\hline GSTA1 & Glutathione S-transferase alpha 1 & Up & $\begin{array}{l}\text { Glutathione metabolic } \\
\text { process }\end{array}$ & $\begin{array}{l}\text { Conjugation of reduced glutathione to a } \\
\text { wide number of exogenous and endogenous } \\
\text { hydrophobic electrophiles }\end{array}$ \\
\hline KNG1 & Kininogen 1 & Up & Inflammatory response & $\begin{array}{l}\text { Multiple function, high molecular weight kininogen } \\
\text { (HMWK) involved in blood coagulation }\end{array}$ \\
\hline RPL10 & Ribosomal protein L10 & Up & Translation & Component of the large 605 ribosomal subunit \\
\hline RPL19 & Ribosomal protein L19 & Up & Translation & Component of the large 605 ribosomal subunit \\
\hline RPL3 & Ribosomal protein L3 & Up & Translation & Component of the large 605 ribosomal subunit \\
\hline TSTD1 & $\begin{array}{l}\text { Thiosulfate sulfurtransferase } \\
\text { (rhodanese)-like domain } \\
\text { containing } 1\end{array}$ & Up & Tumorigenesis? & $\begin{array}{l}\text { Highly expressed in liver, possible role in } \\
\text { tumorigenesis }\end{array}$ \\
\hline BTF3 & Basic transcription factor 3 & Down & Regulation of transcription & Required for the initiation of transcription \\
\hline CPN1 & $\begin{array}{l}\text { Carboxypeptidase } \mathrm{N}, \\
\text { polypeptide } 1\end{array}$ & Down & Proteolysis & $\begin{array}{l}\text { Protects the body from potent vasoactive and } \\
\text { inflammatory peptides released into the circulation }\end{array}$ \\
\hline EIF3C/EIF3CL & $\begin{array}{l}\text { Eukaryotic translation initiation } \\
\text { factor } 3 \text {, subunit C/-like }\end{array}$ & Down & Initiation of protein synthesis & $\begin{array}{l}\text { Component of the eukaryotic translation initiation } \\
\text { factor } 3\end{array}$ \\
\hline H2AFV & $\mathrm{H} 2 \mathrm{~A}$ histone family, member $\mathrm{V}$ & Down & Nucleosome assembly & $\begin{array}{l}\text { Play a central role in transcription regulation, DNA } \\
\text { repair, DNA replication and chromosomal stability }\end{array}$ \\
\hline HTRA1 & $\begin{array}{l}\text { High-temperature requirement } \\
\text { A serine peptidase } 1\end{array}$ & Down & $\begin{array}{l}\text { Regulation of cell } \\
\text { growth/proteolysis }\end{array}$ & $\begin{array}{l}\text { Serine protease with a variety of targets. Regulates } \\
\text { the availability of insulin-like growth factors (IGFs) }\end{array}$ \\
\hline NDUFS1 & $\begin{array}{l}\text { NADH dehydrogenase (ubiquinone) } \\
\text { Fe-S protein 1, } 75 \mathrm{kDa} \\
\text { (NADH-coenzyme Q reductase) }\end{array}$ & Down & $\begin{array}{l}\text { Mitochondrial electron } \\
\text { transport, NADH to } \\
\text { ubiquinone }\end{array}$ & $\begin{array}{l}\text { Core subunit of the mitochondrial membrane } \\
\text { respiratory chain } \mathrm{NADH} \text { dehydrogenase }\end{array}$ \\
\hline PABPC 1 & $\begin{array}{l}\text { Poly(A) binding protein, } \\
\text { cytoplasmic } 1\end{array}$ & Down & mRNA polyadenylation & $\begin{array}{l}\text { May be involved in cytoplasmic regulatory } \\
\text { processes of mRNA metabolism }\end{array}$ \\
\hline PNP & Purine nucleoside phosphorylase & Down & $\begin{array}{l}\text { Nucleobase-containing } \\
\text { compound metabolic } \\
\text { process }\end{array}$ & Catalyze phosphorolysis of purine nucleosides \\
\hline PSAP & Prosaposin & Down & Lipid metabolic process & $\begin{array}{l}\text { Catabolism of glycosphingolipids with short } \\
\text { oligosaccharide groups }\end{array}$ \\
\hline
\end{tabular}

growth/catabolism (IGFBP1A) and five genes (CYP1A, HSP90B, NDUFS1, MTOR and PSMC2) selected from the cDNA library gene lists (Figure 6) were included for analysis. CuZn SOD showed a decreasing expression with increasing temperature, and was significantly lower expressed in liver of fish kept at $17^{\circ} \mathrm{C}$ and $19^{\circ} \mathrm{C}$ compared to the control fish kept at $13^{\circ} \mathrm{C}$ (Figure 6A). Mn SOD was significantly lower expressed in fish kept at $19^{\circ} \mathrm{C}$ com- pared to the fish kept at $13^{\circ} \mathrm{C}$ (Figure 6B). Significant lower expression in fish kept at the two highest temperatures compared to the control fish was also observed for GPx1 (Figure 6D), GR (Figure 6E), HIF1A (Figure 6F) and CYP1A (Figure 6G). MTOR (Figure 6I) and PSMC2 (Figure 6L) expression was significantly lower in the fish kept at $19^{\circ} \mathrm{C}$ compared to the $13^{\circ} \mathrm{C}$ control, whereas no significant effects of temperature stress were observed 


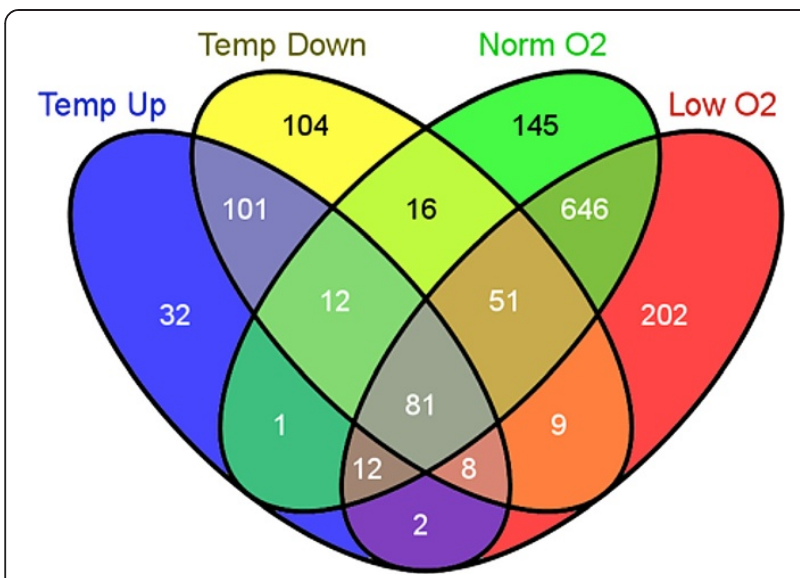

Figure 5 Venn diagram displaying the number of significantly differentially expressed transcripts in Atlantic salmon exposed to temperature stress at $19^{\circ} \mathrm{C}$ (separated into up- and down-regulated transcripts) compared to fish kept at optimal temperature at $13^{\circ} \mathrm{C}$. Based on contigs assembled from more than 50 reads with IPA readable human identifiers.

between the groups for CAT (Figure 6C), IGFBP1A (Figure 6H) and NDUFS1 (Figure 6J). Significance levels are shown in the figures.

Figures 7 and 8 show the transcriptional levels of 13 genes in liver of a total of 54 individual fish obtained from the low oxygen stress experiment. The fish were collected from six treatment groups, three that were fed high-energy diets and three that were fed low-energy diets. From each dietary group fish were either kept at normoxia (control), low oxygen or pair fed. 2-way ANOVA was used to search for effects of oxygen levels and dietary energy levels. The amount of energy in the feed had a stronger effect on the transcriptional levels than oxygen saturation levels. Significant effects of feed energy were observed for CuZn SOD (Figure 7A), Mn SOD (Figure 7B), CAT (Figure 7C), GR (Figure 7D), HSP70 (Figure 7E), HSP90A (Figure 7F), CYP1A (Figure 7H), and PSMC2 (Figure 8E). Significant effects of water oxygen saturation were observed for GR (Figure 7D), and IGFBP1B (Figure 8B). Interaction effects between feed energy content and water oxygen saturation were observed for GR (Figure 7D), and IGFBP1B (Figure 8B). Only two out of the 13 evaluated genes showed a significant effect of low oxygen exposure according to the RT-qPCR data by comparing the normoxia and low oxygen groups directly (high energy and low energy feed groups combined). Hypoxic condition resulted in lowered GR transcription (Figure 7D, t-test, $\mathrm{P}=0.04, \mathrm{n}=18$ ) and increased IGFBP1B transcription (Figure 8B, t-test, $\mathrm{P}=0.0049, \mathrm{n}=18$ ).

Correlation analyses of the individual RT-qPCR transcript data from the temperature and low oxygen stress experiments are shown in Additional file 5. From the temperature stress experiment, many of the evaluated target gene transcripts were strongly correlated with each other (Additional file 5, worksheet A). For example, the transcriptional level of HIF1A in these individuals was positively correlated with CuZn SOD, Mn SOD, GR, GPx1, MTOR, CYP1A, NDUFS1 and PSMC2 (Spearman's rank-order correlation, $\mathrm{R}>0.75$ ). Many of the transcripts encoding oxidative stress markers were strongly correlated in fish exposed to heat stress.

To compare correlations of transcripts from the low oxygen exposure experiment, we combined the control normoxia fish from the high and low energy feeding groups $(n=18)$, and the low oxygen-exposed fish from the two dietary groups $(\mathrm{n}=18)$, to search for altered correlations in fish kept at suboptimal oxygen saturation for 120 days (data shown in Additional file 5, worksheet B). HIF1A transcription was positively correlated to CuZn SOD and PSMC2 transcription in the low oxygen-exposed fish, but not in the control fish (Spearman's rank-order correlation, $R>0.47$ ). For most of the evaluated oxidative stress marker genes, low oxygen exposure induced few changed transcript correlations, except for Mn SOD that showed stronger correlations with NDUFS1 and PSMC2 in fish kept at low oxygen. NDUFS1, one of the genes selected from the cDNA libraries as a potential marker of both temperature and low oxygen stress, was positively correlated with IGFBP1A and PSMC2 in the low oxygenexposed fish, but not in the control fish. Both HSP70 and HSP90A were positively correlated with IGFBP1B in the low oxygen-exposed fish, but not in the control fish. CYP1A, a much-studied biomarker that easily changes expression after environmental stress, showed several low oxygen-mediated correlations, including positive correlations with $\mathrm{CuZn}$ SOD, Mn SOD, CAT, MTOR and HSP70. Additional file 6 shows sequences in Fasta format of all assembled contigs from the four cDNA libraries (A-D) discussed in this work.

\section{Discussion}

In this work we wanted to compare the transcriptional responses to chronic high temperature and low oxygen stress in Atlantic salmon to elucidate possible negative effects on farmed Atlantic salmon as a consequence of climate change. To do so we obtained samples from two independent experiments, one temperature stress experiment conducted in 2009 and described by Hevrøy et al. [30], and one low oxygen stress experiment conducted in 2011. Global transcriptional profiling data were obtained from four cDNA libraries sequenced with 454 FLX technology. IPA Upstream Regulator analysis aims to identify which transcriptional regulators that may be responsible for the observed change in a dataset, and was used for comparison of the two datasets. Based on the suggested upstream regulators the two stressors seem to affect many transcription factors regulating 


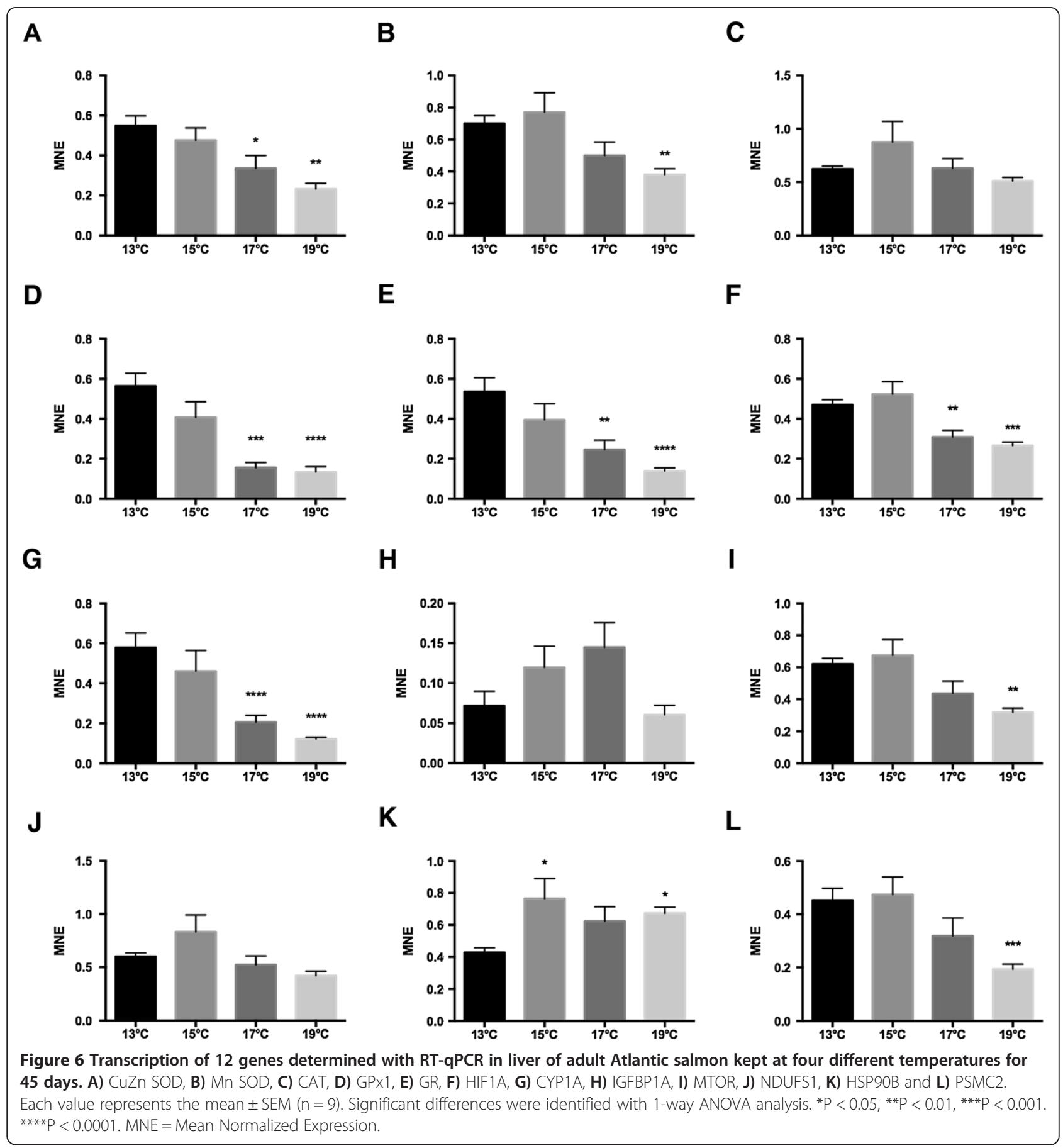

similar processes in liver cells. In line with established knowledge, at the molecular level these stressors appear to affect the rate of protein synthesis and lead to a metabolic rate suppression that ultimately results in reduced growth. This study thus suggests that both temperature stress and low oxygen induce metabolic depression in Atlantic salmon.

In general, many genes were significantly down-regulated in fish exposed to $19^{\circ} \mathrm{C}$ compared to the control fish kept at optimal condition at $13^{\circ} \mathrm{C}$. This pattern was verified with the RT-qPCR analyses. Fish held at $15^{\circ} \mathrm{C}$ or above had reduced growth compared to the controls. In ectoderms, abiotic factors such as temperature determine the amount of energy spent on maintenance and growth, as most biological processes, i.e. protein synthesis and degradation, are temperature dependent. At temperatures above optimal reduced growth is inevitable [5], as recently shown in longtime elevated temperature experiments with 


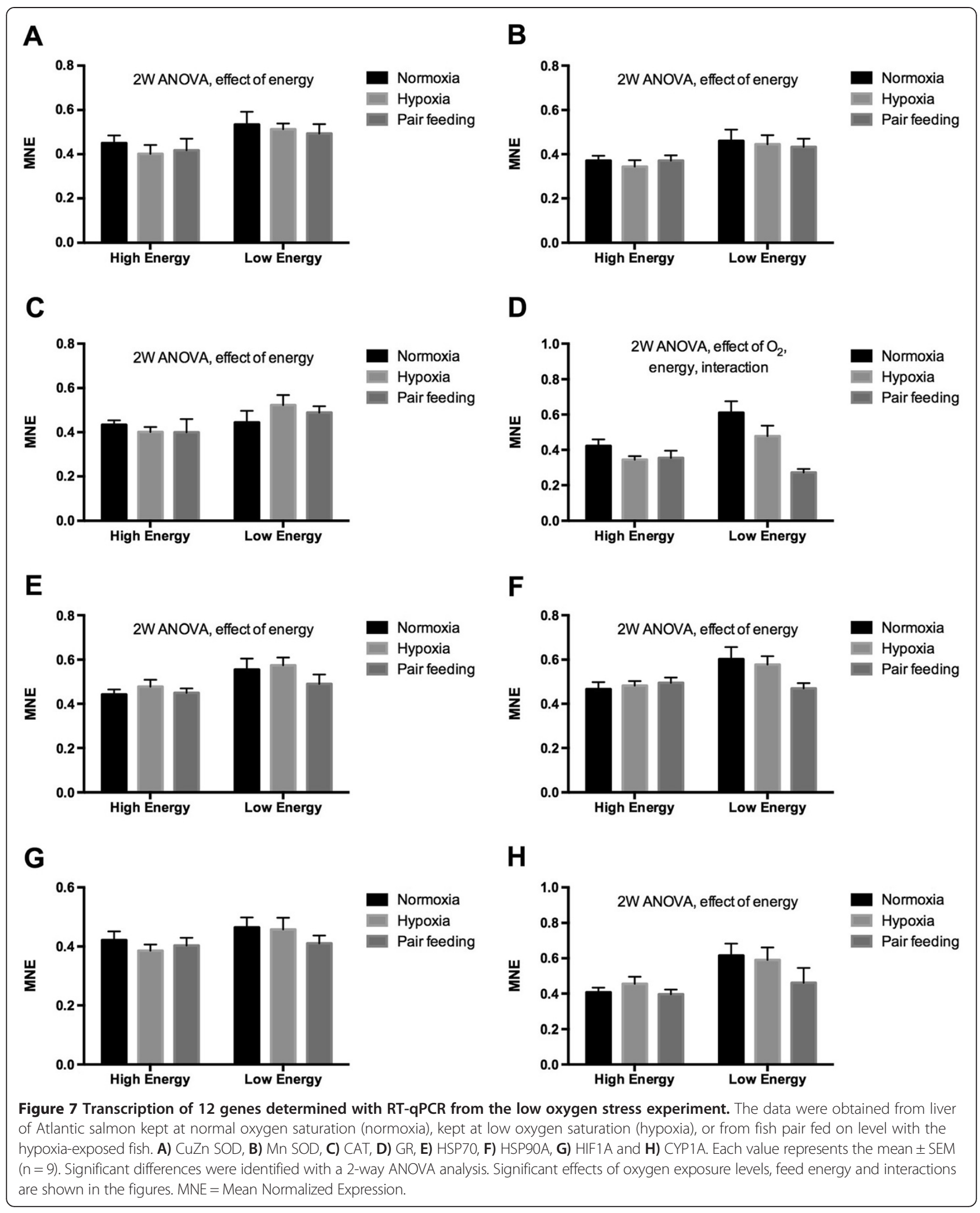




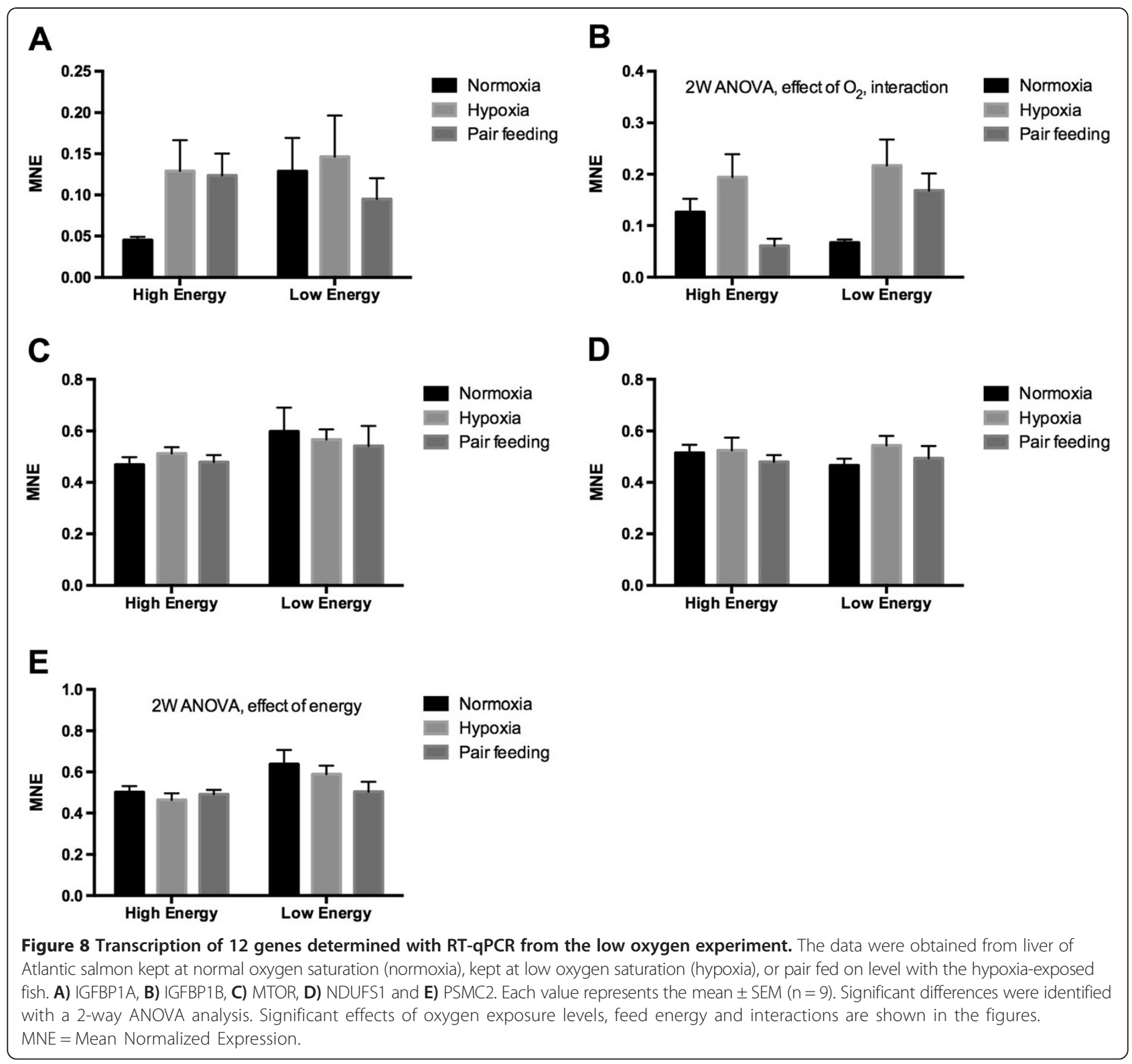

Atlantic salmon [6,30]. The current study shows that long-term exposure to sub-optimal oxygen saturation also has a negative effect on growth in Atlantic salmon. The growth effects of hypoxia are often explained in terms of loss of appetite and assimilation efficiency, and in terms of digestion [32]. A similar loss of appetite has been shown in large Atlantic salmon continuously exposed to $19^{\circ} \mathrm{C}$ [4]. At the cellular level, protein synthesis and ion-pumping through $\mathrm{Na}, \mathrm{K}$-ATPase represent key targets of hypoxia causing energy reallocation [33]. By comparing the two datasets, temperature and low oxygen stress seem to induce effects involving many similar mechanisms. However, surprisingly few of the top-ranked genes in the cDNA libraries were common between the two treatments. Only 19 contigs with similar annotation were identified as being affected both by temperature and low oxygen. This suggests that although chronic high temperature and low oxygen stress affects many identical mechanism in fish, they do not necessary invoke these effects through differential regulation of the same individual genes. The low degree of overlap may in part rely on the two different methods applied for cDNA library construction, as discussed below. In marine environments it is generally held that dissolved oxygen concentrations below 2-3 $\mathrm{mg} \mathrm{O}_{2} / \mathrm{L}$ is considered hypoxic [17]. By this definition, the low oxygen stress used in the current experiment did not account as hypoxia, but for simplicity we use the "low oxygen stress" and "hypoxia" terms interchangeable throughout the discussion. In coldwater salmonids, behavioral responses to hypoxia have been detected already at $8 \mathrm{mg} \mathrm{O}_{2} / \mathrm{L}$ [34], but dissolved 
oxygen conditions below $6 \mathrm{mg} \mathrm{O} / \mathrm{L}$ is generally regarded as hypoxic for Atlantic salmon $[19,35]$. Whether the observed responses reported here should be considered as stress or allostasis [36] is arguable, but animals experiencing long-term disturbances will tend to adjust their physiology toward normal homeostasis. Even so, over time these moderate stressors may have a negative impact on fitness, as suggested by the reduced growth seen in both experiments.

Interestingly, temperature stress appears to downregulate several important liver transcription regulators. MYCN, HNF1A, HNF4A and NFE2L2 were among the transcription regulators that were inhibited by high temperature. This finding suggests that heat stress may have had an effect on the transcriptional rate in salmon liver. At the same time, most of the upstream regulators with a predicted activated state are typically associated with responses induced by chemical drugs. Thus, the key liver transcriptional factors affected by temperature stress suggest an effect on overall transcription, while at the same time the environmental stimuli seems to induce transcription of genes most often linked to effects of toxicants. The results suggest a switch toward increased transcription of protective enzymes at the cost of synthesis of maintenance enzymes. Based on the RTqPCR results from the heat stress study, it appears clear that liver transcription in Atlantic salmon is considerable affected at temperatures above $17^{\circ} \mathrm{C}$. Of the evaluated markers for oxidative stress, four out of five genes, $\mathrm{CuZn}$ SOD, Mn SOD, GPx1 and GR, were lower expressed in liver of fish kept at $19^{\circ} \mathrm{C}$ than in fish kept at optimal temperature at $13^{\circ} \mathrm{C}$, while three genes, CuZn SOD, GPx1 and GR, also showed significant lower expression in fish kept at $17^{\circ} \mathrm{C}$. This could be due to reduced mitochondrial ROS production as a result of reduced overall metabolism at higher temperature, although, in general, elevated environmental temperature results in enhanced oxygen consumption and ROS production and thereby increased oxidative stress in fish [37]. High temperature mediated lower expression of several of the other evaluated genes also, including HIF1A. The only gene that showed a significant higher expression in heat-stressed fish was HSP90B. In heat stressed fish, HSP90B was positively correlated with HSP70, but this transcript showed no significant correlation with any of the other evaluated genes, as opposed to for example HIF1A, whose expression was significantly correlated with all evaluated transcripts except for the two heat shock protein transcripts HSP70 and HSP90B.

Several overrepresented GO terms in fish exposed to low oxygen were associated with tissue development and growth. The GO enrichment analysis thus suggests a distinct response to low oxygen at the molecular level, with the sub-optimal oxygen concentration affecting transcripts encoding proteins important for continued growth. According to the IPA analysis, hypoxia induced effects on "organismal development" including lipid and nucleic acid metabolism at the molecular level, with protein ubiquitination as the most strongly affected pathway. The predicted top upstream regulators, 1,2-dithiol-3-thione, sirolimus, pirintrix acid, CD437 and 5-fluorouracil, suggest an effect leading to increased apoptosis and negative weight gain. Glutathione depletion and signaling effects possibly induced by nuclear factor (erythroid-derived 2)like 2 (NFE2L2) in the liver seems a likely explanation for these findings. NFE2L2 is a transcription activator that binds to antioxidant response elements (ARE) in the promoter regions of target genes important for the coordinated regulation of genes in response to oxidative stress [38]. Of the oxidative stress marker genes evaluated with RT-qPCR, only GR showed a significant effect of low oxygen treatment. GR is crucial in glutathione metabolism and maintains high levels of reduced glutathione in the cytosol. In a previous study in which Atlantic cod (Gadus morhua) were exposed to $46 \% \mathrm{O}_{2}$ saturation for six weeks, we observed down-regulation of transcripts encoding CuZn SOD and GPx3 [39]. Altered regulation of genes involved in glutathione metabolism strengthens the predicted effect of hypoxia on NFE2L2 regulated oxidative stress markers. Three of the predicted five top significant upstream regulators induced by hypoxia were also among the top five most significant upstream regulators induced by temperature stress, i.e. 5-fluorouracil, CD437 and sirolimus, suggesting a partly overlapping response to the two stressors.

A compelling finding was that among the 19 common genes were two transcripts encoding proteins typically involved in detoxification of persistent organic pollutants (POPs), i.e. CYP1A and GSTA1. Both transcripts were higher expressed in temperature-stressed fish liver. Due to the high fat content in muscle, farmed Atlantic salmon are prone to accumulate relatively high levels of lipophilic POPs in fillet and liver [40]. One can therefore speculate that elevated temperature may have affected the storage and turnover of POPs in salmon muscle and liver, as influx and efflux rates of toxicants across membranes increase with increasing temperature [29]. In temperature-stressed salmon, lipids stored in muscle tissue are increasingly being used for maintenance energy metabolism [30]. EROD activity is temperature dependent in fish $[41,42]$, so if increased EROD activity over time is followed by increased transcription, a temperature effect on CYP1A transcription might be expected. In gills of rainbow trout (Oncorhynchus mykiss) held at 8 or $23^{\circ} \mathrm{C}$ for two weeks, heat stress up-regulated several drug-metabolizing protein transcripts including phase I and II enzyme transcripts such as CYP1A, CYP1C1, UGT2B17, and xenobiotic transporter ABCG2 [43], clearly suggesting a temperature effect 
on drug-metabolizing enzyme transcription in salmonids. Since both aryl hydrocarbon receptor (AhR) and HIF-1 compete for aryl hydrocarbon nuclear translocator (ARNT), hypoxia could be expected to decrease the expression of P450 genes [44]. Indeed, in Atlantic cod exposed to $46 \%$ hypoxia for six weeks we observed CYP1A transcript down-regulation [39]. Rahman and Thomas [45] also observed a down-regulation of CYP1A mRNA and protein levels in liver of Atlantic croaker (Micropogonias undulatus) exposed to hypoxia (dissolved oxygen, DO: $1.7 \mathrm{mg} / \mathrm{L}$ for 2 to 4 weeks) compared to fish held in normoxic condition, and suggested that hypoxia-induced down-regulation of CYP1A is due to alterations of nitric oxide and oxidant status, and cellular IL-1beta and HIFalpha levels. In threespine stickleback (Gasterosteus aculeatus) acutely exposed to hypoxia for 4-48 hours, Leveelahti et al. [46], however, observed increased expression of CYP1A2 mRNA, a finding also confirmed at the protein level by EROD activity measurement. These findings suggest that hypoxia exposure may affect the expression of AhR-mediated P450 genes. The reason for the altered transcription of CYP1A in hypoxia-stressed fish, which we were not able to independently verify with RTqPCR in the current work, should be studied further.

Metabolic responses to ensure cell survival during hypoxia exposure involve metabolic reorganization to decrease ATP demands to match the reduced capacity for ATP production [47]. Several signal transduction cascades, including AMP-activated protein kinase (AMPK) and HIF-1, are activated in response to hypoxia in fishes and other vertebrates $[48,49]$. AMPK activation in mammals inhibits energetically costly anabolic processes such as protein synthesis, glycogen synthesis, and fatty acid synthesis rates [47]. One AMPK gene, the 5-amp-activated protein kinase subunit beta-1 (PRKAB1), was found included in our dataset from the low oxygen exposure gene list but was not present in the normoxia library gene list. The PRKAB1 subunit of AMPK may be a positive regulator of AMPK activity [38]. Also present in the hypoxia gene list but not present in the normoxia gene list was the hypoxia-inducible factor 1A (HIF1A). HIF1A is a transcription factor that functions as a master regulator of gene expression in response to hypoxia [50]. HIF-1 protein is a heterodimer composed of an alpha and a beta subunit that is involved in cellular processes such as energy metabolism, apoptosis, proliferation, death and growth. Both acute and chronic hypoxia can distinctly affect mRNA levels of HIF-1, and this gene has been suggested as a reliable fish biomarker of hypoxia exposure [51]. Heat treatment mediated a reduced expression of HIF1A mRNA in liver of Atlantic salmon. According to the RT-qPCR data HIF1A transcription appeared to be stimulated at moderate heat stress $\left(15^{\circ} \mathrm{C}\right)$, but was significantly lower at more severe heat stress $\left(17-19^{\circ} \mathrm{C}\right)$. A similar response pattern has been observed in the North Sea eelpout (Zoarces viviparous), with elevated DNA binding activity of HIF-1 during mild heat exposure $\left(18^{\circ} \mathrm{C}\right)$ but impaired activity at more severe heat stress [35]. A possible link between temperature and HIF-1 activity has previously also been shown for crucian carp (Carassius carassius) [52].

Insulin-like growth factors binding proteins (IGFBPs) play important roles in down-regulating IGF availability and cell growth and development in vertebrates exposed to hypoxic stress [53]. Gracey et al. [20] observed increased transcription of IGFBP1 in liver of longjaw mudsucker and shortjaw mudsucker (Gillichthys seta) after acute exposure to hypoxia, in line with our finding. In zebrafish embryos it has been shown that hypoxia strongly induces transcription of the IGFBP1 [54,55]. Overexpression of IGFBP1 resulted in reduced growth in zebrafish embryos under normoxic condition, suggesting that the IGFBP1 protein plays an important role on fish growth during hypoxia and may even be an activator of the HIF-1 system. In line with our finding, Rahman and Thomas [53] found that chronic hypoxia exposure (24 weeks) caused significant increase in liver IGFBP1 mRNA in Atlantic croaker. IGFBP1 transcription thus appears to be a good biomarker for chronic hypoxia also in Atlantic salmon. Two IGFBP1 genes have been found in Atlantic salmon possibility due to whole genome duplication [56,57], and these seem to be differentially regulated at the transcriptional level in liver after chronic low oxygen stress but not after temperature stress. Heat stress, induced by a temperature increase from $13^{\circ} \mathrm{C}$ to $17^{\circ} \mathrm{C}$, appears to increase the transcription of both IGFBP1A (this study) and IGFBP1B [30] in Atlantic salmon. Chronic low oxygen stress mediated a significant change only for the IGFBP1B ortholog.

Both applied cDNA library construction methods represent a semi-quantitative measure of transcript abundance. SSH cDNA libraries are prone to false positives, whereas normalized cDNA libraries, by removing highabundant rRNA transcripts, increase sequence coverage depth and transcript diversity across non-rRNA populations [58]. For this reason we have not attempted to compare the libraries quantitatively. By using pooled samples, and two different library construction methods, the RNA-seq data presented here should be considered indicative rather than exact quantitative measures of molecular effects of treatments that mitigate effects at the physiological level, i.e. reduced growth. As expected, fewer large contigs, contigs of at least $500 \mathrm{bp}$, were obtained by using SSH cDNA libraries than by using normalized cDNA libraries. With SSH technology, about 2000 large contigs were obtained from the heat stress experiment, whereas about 8000 large contigs were obtained from the normalized libraries. More equal numbers 
were obtained from the four cDNA libraries by selecting contigs consisting of more than 50 reads for the functional analyses. The selected strategy may have created a bias toward higher expressed genes, but represents a trade-off between confounding the pathway analysis by using too many input genes and lost strength by not including enough low-expressed genes.

Additionally, duplicated salmon co-orthologs may represent a problem in comparing the RNA-seq and RTqPCR data. Co-orthologs with high sequence similarity may show differential expression but obtain similar best annotation. This phenomenon may explain the apparently contradictory finding for the CYP1A gene. According to the SSH library data, CYP1A was up-regulated by heat stress, while at the same time the RT-qPCR analysis suggested CYP1A to be down-regulated. Differential expression of orthologous HIF1A genes has recently been described in cyprinids, with one of the orthologs being more sensitive to oxygen tension [59]. At present, no information on orthologous HIF1A genes and their potential differential regulation are available for Atlantic salmon.

\section{Conclusions}

This study suggests that environmental stress such as high temperature and low oxygen saturation, possibly becoming more widespread by global warming, may negatively affect growth in farmed Atlantic salmon. While heat stress in general appears to reduce the overall transcriptional rate, increased protein catabolism appears to be one of the main effects of low oxygen saturation stress. Predicted upstream transcriptional regulators suggest that the two types of stress affect many identical mechanisms in liver cells resulting in a metabolic depression.

\section{Methods}

\section{Animal trial and experimental feeds}

The temperature experiment was conducted at Matre Research Station, Institute of Marine Research, Matredal, Norway $\left(61^{\circ} \mathrm{N}\right)$. Large immature Atlantic salmon (NLA strain) with a body mass of $1.6 \pm 0.1 \mathrm{~kg}$ were randomly distributed into $123 \mathrm{~m}^{2}$ indoor tanks on August 6, 2009. After acclimation, on October 2, 2009, temperatures were adjusted to $13^{\circ} \mathrm{C}, 15^{\circ} \mathrm{C}, 17^{\circ} \mathrm{C}$ and $19^{\circ} \mathrm{C}$, with triplicate tanks in $35 \mathrm{~g} / \mathrm{L}$ seawater for each temperature and oxygen levels at $90 \%$ saturation $\left(8 \mathrm{mg}\right.$ and $6 \mathrm{mg} \mathrm{O} \mathrm{O}_{2} / \mathrm{L}$ at 13 and $19^{\circ} \mathrm{C}$, respectively). Temperatures were maintained at these levels until fish sampling on November 16 after 45 days of exposure. All fish were fed a commercial diet (Optiline, Skretting ARC, Stavanger, Norway). The feed contained $34.9 \%$ lipid, $37.9 \%$ protein, $5.8 \%$ ash, and $6.2 \%$ moisture, and had a gross energy content of $21.7 \mathrm{MJ} / \mathrm{kg}$ digestible energy (DE). At the end of the experiment, 36 fish, with nine fish from each treatment (three from each of the triplicate tanks with similar treatment) were collected 4 hours postprandial for weight and length measurements and tissue collection. The fish were killed with a blow to the head without sedation. Liver tissue samples for RNA extraction were immediately dissected out and flash frozen on liquid nitrogen, and stored at $80^{\circ} \mathrm{C}$ until further analysis. A detailed description of this experiment, including feeding and fish husbandry, is given in Hevrøy et al. [30].

The low oxygen experiment was conducted at Lerang Research Station, Skretting AS, Lerang, Norway $\left(59^{\circ} \mathrm{N}\right)$ between April and August, 2011. Immature Atlantic salmon of NLA strain weighing between 1.5-2.0 kg were distributed into $3 \mathrm{~m}^{2}$ tanks on April 11, 2011. All fish were pit tagged prior to the experiment. Using triplicate tanks for each treatment, Atlantic salmon were divided into 18 tanks and given six different treatments. Half of the fish were fed a high-energy diet (22 MJ DE, 9 tanks), and the other half a low-energy diet where lipids were exchanged with carbohydrate (20.5 MJ DE, 9 tanks). The high-energy diet contained $36.9 \%$ lipid, $38.7 \%$ protein, $5.0 \%$ ash and $5.5 \%$ moisture, while the low-energy diet contained $31.6 \%$ lipid, $36.4 \%$ protein, $5.0 \%$ ash and $6.5 \%$ moisture. One group of fish was fed a diet containing the same energy level as fish kept at low oxygen, called pair feeding to discriminate feed intake effects. The fish were presented with the following three different treatments; optimum oxygen (7-8 $\mathrm{mg} \mathrm{O}_{2} / \mathrm{L}$ ), optimum oxygen with pair feeding (7$8 \mathrm{mg} \mathrm{O}_{2} / \mathrm{L}$ ), or low oxygen (4-5 $\mathrm{mg} \mathrm{O}_{2} / \mathrm{L}$ ) all in triplicate tanks $(n=9, N=54)$. Low oxygen levels were simulating typical natural farming conditions [60], with cyclic low dissolved oxygen levels during night and increased normal levels during day with average $6 \mathrm{mg} \mathrm{O}_{2} / \mathrm{L}$ between 12:0018:00 h. Temperature was kept constant at $12^{\circ} \mathrm{C}$ during the trial with stable $35 \mathrm{~g} / \mathrm{L}$ seawater and the fish were reared under a simulated natural photoperiod. In total 54 fish were sampled 4 hours postprandial after four months of treatment on August 23, 2011. Liver tissue samples for RNA extraction were immediately dissected out and flash frozen on liquid nitrogen, and stored at $80^{\circ} \mathrm{C}$ until further analysis. The experiment complied with the guidelines of the Norwegian Regulation on Animal Experimentation and EC Directive 86/609/EEC, and the National Animal Research Authority approved the protocol.

\section{Biological performance data}

During the experiments, daily feed intake was monitored to secure optimal growth recordings (detailed description given in Hevrøy et al. [30]; Vibeke Vikeså, unpublished results). All fish were recorded for weight and fork length to the nearest $g$ and nearest $0.5 \mathrm{~cm}$ at the start and at end of the experiments $(\mathrm{N}=538$ and $\mathrm{N}=990$, temperature and low DO trial). To obtain comparable relation in somatic 
growth measurements, thermal growth coefficients were determined. The thermal growth coefficient (TGC) was calculated as TGC $=\left(\left(\mathrm{W}_{2}^{0.333}-\mathrm{W}_{1}^{0.333}\right) /\left(\Sigma \mathrm{C}^{\circ}\right)\right) \times 1000$, where $W_{1}$ and $W_{2}$ are initial and final body mass in grams and $\Sigma \mathrm{C}^{\circ}$ are sum day-degree in the experiment.

\section{RNA isolation}

Liver tissues from the Atlantic salmon were thoroughly homogenized before RNA extraction using a Precellys 24 homogenizer by ceramic beads CK28 (Bertin Technologies, Montigny-le-Bretonneux, France). Total RNA was extracted using the BioRobot EZ1 and RNA Tissue Mini Kit (Qiagen, Hilden, Germany) and treated with DNase according to the manufacturer's instructions and eluted in $50 \mu \mathrm{L}$ RNase-free MilliQ $\mathrm{H}_{2} \mathrm{O}$. The RNA was then stored at $-80^{\circ} \mathrm{C}$ before further processing. RNA quality and integrity were assessed with the NanoDrop ND-1000 UV-Vis Spectrophotometer (NanoDrop Technologies, Wilmington, DE, USA) and the Agilent 2100 Bioanalyzer (Agilent Technologies, Palo Alto, CA, USA). The RNA 6000 Nano LabChip kit (Agilent Technologies, Palo Alto, CA, USA) was used to evaluate the RNA integrity of the liver samples. The 260/280 and 260/ $230 \mathrm{~nm}$ ratios of the extracted RNA were $2.1 \pm 0.0$ and $2.1 \pm 0.0$, respectively (mean $\pm \mathrm{SD}$ ). The RNA integrity numbers (RIN) of the liver samples used for RT-qPCR from the temperature stress and hypoxia cDNA libraries were 9.6 $\pm 0.1(n=36)$ and $8.8 \pm 0.3(n=54)($ mean $\pm S D)$, respectively.

\section{Suppressive subtractive hybridization (SSH) and normalized cDNA library construction}

Pooled RNA from liver of Atlantic salmon from four treatment groups $\left(13^{\circ} \mathrm{C}\right.$ versus $19^{\circ} \mathrm{C}$, and normoxia versus low $\mathrm{O}_{2}$ ) was used to construct cDNA libraries for sequencing. From the heat stress experiment, we pooled RNA from six fish from the control group and six fish from the high temperature group for construction of two suppressive subtractive hybridization ( $\mathrm{SSH}$ ) cDNA libraries. Pooled RNA, obtained from nine individuals from the normoxia and nine individuals from low oxygen experimental groups fed high-energy diets, was used to create the normalized cDNA libraries.

SSH was performed using the Clontech PCR Select cDNA Subtraction Kit (Clontech, Mountain View, CA) following the manufacturer's recommendations. cDNA subtraction was performed in both directions. Forward subtracted libraries were designed to be enriched for genes that were up-regulated in liver of Atlantic salmon by heat stress $\left(19^{\circ} \mathrm{C}\right)$, and reverse subtracted libraries were designed to be enriched for genes that were downregulated by heat stress. Pooled mRNA samples from liver of fish exposed to $19^{\circ} \mathrm{C}$ were used as testers in the forward subtractions and as drivers in the reverse subtractions. Pooled mRNA samples from liver of fish held at $13^{\circ} \mathrm{C}$ were used as drivers in the forward subtractions and as testers in the reverse subtractions. To evaluate subtraction efficiency, the abundance of transcripts of the housekeeping gene ubiquitin was examined by PCR. For SSH cDNA libraries, mRNA from each sample was isolated using the NucleoTrap mRNA Mini Kit (MachereyNagel, Düren, Germany). The Agilent Bioanalyzer with the RNA 6000 Nano LabChip kit and the DNA 7500 Kit (Agilent Technologies, Waldbronn, Germany) was used to evaluate the quality of the mRNA and cDNA samples used for cDNA library construction. $200 \mathrm{ng}$ of mRNA from each sample was used for cDNA synthesis according to the GS FLX Titanium Rapid Library Preparation Kit (Roche Applied Sciences, Basel, Switzerland).

For normalized cDNA library construction, mRNA was purified from $10 \mu \mathrm{g}$ total RNA by exonuclease digestion followed by $\mathrm{LiCl}$ precipitation (mRNA-Only Eucaryotic mRNA Isolation Kit, Epicentre, Madison, WI, USA). $1 \mu \mathrm{g}$ mRNA was used for first-strand cDNA synthesis. cDNA synthesis and amplification was done according to the Mint-Universal cDNA Synthesis Kit user manual (Evrogen, Moscow, Russia). 800 ng amplified cDNA was used as starting material in the normalization reaction using the Trimmer Kit (Evrogen, Moscow, Russia). Normalized material was re-amplified for 18 cycles. $2 \mu \mathrm{g}$ of normalized cDNA was digested with 10 Units Sfil for 2 hours at $48^{\circ} \mathrm{C}$. Fragments larger than 800 bp were isolated from a LMP Agarose Gel and purified using the MinElute Gel Extraction Kit (Qiagen, Hilden, Germany). $200 \mathrm{ng}$ purified cDNA fragments were ligated to $100 \mathrm{ng}$ Sfi cut and dephosphorylated pDNR-lib Vector (Clontech) in $10 \mu \mathrm{L}$ volume using the Fast Ligation Kit (NEB, Ipswich, MA, USA). Ligations were desalted by ethanol precipitation, and re-dissolved in $10 \mu \mathrm{L}$ water. 3 times $1.5 \mu \mathrm{L}$ desalted ligation was used to transform NEB10b competent cells (NEB, Ipswich, MA, USA). 96 clones were randomly chosen for Sanger sequencing to verify successful normalization. For each library roughly 2 million clones were plated on LB-Cm plates, scrapped off the plates and stored as glycerol stocks at $-70^{\circ} \mathrm{C}$. One half of the cells were used to inoculate a $300 \mathrm{ml}$ Terrific Broth $/ \mathrm{Cm}$ culture, which was grown for 5 hours at $30^{\circ} \mathrm{C}$. Plasmid DNA was prepared using standard methods (Qiagen, Hilden, Germany). $200 \mu \mathrm{g}$ of purified plasmid DNA was digested with 100 Units SfiI for 2 hours at $48^{\circ} \mathrm{C}$. cDNA Inserts were gel purified (LMP-Agarose/MinElute Gel Extraction Kit) and ligated to high-molecular-weight DNA using a proprietary Sfi-linker. Library generation for the 454 FLX sequencing was carried out according to the manufacturer's standard protocols (Roche/454 life sciences, Branford, CT 06405, USA). 


\section{FLX sequencing}

Atlantic salmon liver tissue cDNA libraries from the temperature stress trial were prepared as stated above and sequenced according to the Roche 454 GS FLX protocol using titanium chemistry (Roche 454 Life Sciences, Branford, CT, USA) at the Ultra-high Throughput Sequencing Platform of the Centre for Ecological and Evolutionary Synthesis (CEES), Department of Biology, University of Oslo, Norway. 454 FLX sequencing, data processing and data assembly of the normalized liver cDNA libraries were carried out by LGC Genomics $\mathrm{GmbH}$, Berlin, Germany. Nucleotide sequences were incorporated into quality filtered flowgram (SFF) files using the 454's software and applied in downstream analyses. Library generation for the 454 FLX sequencing of the samples was carried out according to the manufacturers standard protocols (Roche 454 Life Sciences, Branford, CT, USA). Briefly, the concatenated inserts were sheared randomly by nebulization to fragments ranging in size from 400 to $900 \mathrm{bp}$. These fragments were end polished and the $454 \mathrm{~A}$ and $\mathrm{B}$ adaptors that are required for the emulsion PCR and sequencing were added to the ends of the fragments by ligation. The resulting fragment library was sequenced on 3 individual $1 / 4$ picotiter plates (PTP) on the GS FLX using the Roche 454 titanium chemistry.

\section{Clustering, assembly and read processing}

As a quality measure in search for possible microbial contamination, i.e. impurities in the nucleotides under investigation, all reads generated by the FLX sequencer were subjected to taxonomic profiling using MEtaGenome ANalyzer (MEGAN, version 3.9.) using default settings [61]. Reads longer than 50 nt were aligned to the GenBank non-redundant protein database (Blastx) [62] using a cutoff e-value of 1e-6, and the Blast results used as input in the MEGAN analyses.

Prior to assembly the sequence reads were screened for the Sfi-linker that was used for concatenation, the linker sequences were clipped out of the reads and the clipped reads assembled to individual transcripts using the Newbler software version 2.6 at default settings (build: 20110517_1502). SFF files were assembled using the Newbler software with minimum overlap $80 \mathrm{bp}$ and minimum identity 96\% ("-ml 80 -mi 96 -cdna -ace").

\section{Functional analyses}

Four sets of assembled "isotigs" (contigs) were used in the downstream functional analyses from the cDNA libraries. For gene ontology (GO) and Ingenuity Pathway Analysis (IPA) analyses (Ingenuity Systems, Inc., Redwood City, CA, USA), all isotigs consisting of 50 or more reads were used. Blast2GO [63] was used to annotate and analyze all isotigs consisting of 50 reads or more in the four $\mathrm{SSH}$
cDNA library assemblies. Blast2GO analyses were run using a cut-off e-value of 1e-3 (Blastx) and 1e-6 (mapping). GO enrichment analyses were performed with Fisher's exact test applying the GOSSIP tool [64] as integrated in the Blast2GO software.

Gene lists from the four cDNA libraries as annotated with Blast2GO were used for IPA pathway analysis. Since IPA only can map mammalian homolog identifiers, GeneCards IDs were submitted for biological function and pathway analysis, using top Blastx hits and assuming orthologous genes have the same function. A limited number of fish-specific genes with no mammalian homologs were for this reason not included in the pathway analysis. IPA could map and identify $428\left(19^{\circ} \mathrm{C}\right), 639$ $\left(13^{\circ} \mathrm{C}\right), 1281$ (normoxia) and $1341\left(\right.$ low $\left.\mathrm{O}_{2}\right)$ differently expressed genes from the four gene lists, to be included in pathway analyses.

\section{Quantitative real-time RT-qPCR}

PCR primer sequences used for quantification of the transcriptional levels of selected genes, as well as the reference genes, are shown in Table 3. In total 17 genes were quantified with RT-qPCR, of which 3 were selected as potential reference genes. Blastx or Blastn was used to determine PCR assay specificity. The reaction specificity of each assay was checked by examining the melting curves generated with a dissociation protocol from 65 to $97^{\circ} \mathrm{C}$.

RT-qPCR was conducted as previously described by Olsvik et al. [65]. Briefly, a two-step real-time RT-PCR protocol was used to quantify the transcriptional levels of the selected genes. The RT reactions were run in duplicate on a 96-well reaction plate with the GeneAmp PCR 9700 machine (Applied Biosystems, Foster City, CA, USA) using TaqMan Reverse Transcription Reagent

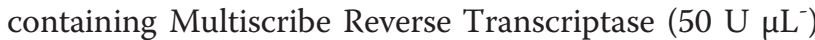
(Applied Biosystems, Foster City, CA, USA). Two-fold serial dilutions of total RNA were made for efficiency calculations. Six serial dilutions (1000-31 ng RNA) in triplicates were analyzed in separate sample wells. Total RNA input was $500 \mathrm{ng}$ in each reaction for all genes. No template controls (ntc) and RT-controls were run for quality assessment for each PCR assay.

Reverse transcription was performed at $48^{\circ} \mathrm{C}$ for $60 \mathrm{~min}$ by using oligo $\mathrm{dT}$ primers $(2.5 \mu \mathrm{M})$ for all genes in $50 \mu \mathrm{L}$ total volume. The final concentration of the other chemicals in each RT reaction was: $\mathrm{MgCl}_{2}$ (5.5 mM), dNTP (500 mM of each), 10X TaqMan RT buffer (1X), RNase inhibitor $\left(0.4 \mathrm{U} \mu \mathrm{L}^{-}\right)$and Multiscribe reverse transcriptase

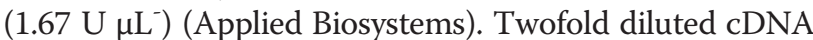
$(2.0 \mu \mathrm{L}$ cDNA in each $\mathrm{RT}$ reaction) was transferred to 384-well reaction plates and the qPCR run in $10 \mu \mathrm{L}$ reactions on the LightCycler 480 Real-Time PCR System (Roche Applied Sciences, Basel, Switzerland). Real-time 
Table 3 PCR assays, including primers sequences, accession numbers, amplicon sizes and PCR efficiencies

\begin{tabular}{|c|c|c|c|c|c|c|}
\hline Gene & Gene product & Accession no. & Forward primer & Reverse primer & $\begin{array}{l}\text { Amplicon } \\
\text { size (bp) }\end{array}$ & PCR efficiency* \\
\hline CuZn SOD & CuZn superoxide dismutase & BG936553 & CCACGTCCATGCCTITGG & TCAGCTGCTGCAGTCACGTT & 140 & $1.92 / 2.02$ \\
\hline Mn SOD & Mn superoxide dismutase & DY718412 & GTTTCTCTCCAGCCTGCTCTAAG & CCGCTCTCCTTGTCGAAGC & 209 & $1.85 / 1.88$ \\
\hline CAT & Catalase & BG935638 & GGGCAACTGGGACCTTACTG & GCATGGCGTCCCTGATAAA & 59 & $1.85 / 2.12$ \\
\hline GPX1 & Glutathione peroxidase 1 & EH033571 & TCTCCTGCCATAACGCTTGA & GTGATGAGCCCATGGCCTTA & 137 & $1.84 /-$ \\
\hline GR & Glutathione reductase & BG934480 & CCAGTGATGGCTIIITTGAACTT & CCGGCCCCCACTATGAC & 61 & $2.00 / 1.91$ \\
\hline HSP70 & Heat shock protein 70 & BG933934 & CCCCTGTCCCTGGGTATTG & CACCAGGCTGGTTGTCTGAGT & 121 & $-/ 1.90$ \\
\hline HIF1A & Hypoxia-inducible factor $1 \mathrm{~A}$ & DY708816 & CCACCTCATGAAGACCCATCA & TCTCCACCCACACAAAGCCT & 101 & $2.20 / 2.26$ \\
\hline IGFBP1A & Insulin-like growth factor binding protein $1 \mathrm{~A}$ & KC122927 & GGTCCCTGTCATGTGGAGTT & TTCCAGAAGGACACACACCA & 184 & $2.10 / 2.08$ \\
\hline IGFBP1B & Insulin-like growth factor binding protein 1B & AY662657 & GAGGACCAGGGACAAGAGAAAGT & GCACCCTCATTTTTGGTGTCA & 101 & $-/ 2.02$ \\
\hline MTOR & $\begin{array}{l}\text { Mechanistic target of rapamycin } \\
\text { (serine/threonine kinase) }\end{array}$ & BT072258 & CAGCCTGAGGCCCTGAATAA & CTCCACTTGGGTTGGCACAT & 114 & $1.97 / 1.95$ \\
\hline CYP1A & Cytochrome P450, family 1 , subfamily A & $\begin{array}{l}\text { >contig00118 length }=2495 \\
\text { numreads }=57\end{array}$ & ATC GGACGCAACGAGGTCTA & TGACAGCGCTTGTGCTTCAT & 128 & $1.97 / 2.02$ \\
\hline NDUFS1 & $\begin{array}{l}\text { NADH dehydrogenase (ubiquinone) } \\
\text { Fe-S protein 1,75 kDa }\end{array}$ & $\begin{array}{l}\text { >contig00384 length }=2136 \\
\text { numreads }=57\end{array}$ & TGCTGCAGGACATCGCTAAC & TGGTTTCACAGAGCTCAAGA & 135 & $1.94 / 2.01$ \\
\hline PSMC2 & $\begin{array}{l}\text { Proteasome (prosome, macropain) } \\
26 \mathrm{~S} \text { subunit, ATPase, } 2\end{array}$ & $\begin{array}{l}\text { >contig01910 length }=1544 \\
\text { numreads }=106\end{array}$ & ATCAGGGTCATCGGCTCAGA & GCCCCTCCAATAGCGTCAAT & 132 & $1.94 / 2.02$ \\
\hline HSP90B & Heat shock protein $90 \mathrm{~B}$ & $\begin{array}{l}\text { >contig03769 length }=1183 \\
\text { numreads }=111\end{array}$ & CCACCATGGGCTACATGATG & CCTTCACCGCCTTGTCATTC & 114 & $1.97 / 1.95$ \\
\hline EEF1AB & $\begin{array}{l}\text { Eukaryotic translation elongation } \\
\text { factor } 1 A B \text { (refgen) }\end{array}$ & AF321836 & CCCCTCCAGGACGTTTACAAA & CACACGGCCCACAGGTACA & 57 & $1.99 / 2.01$ \\
\hline ACTB & Beta-actin (refgen) & BG933897 & CCAAAGCCAACAGGGAGAA & AGGGACAACACTGCCTGGAT & 102 & $2.06 / 1.90$ \\
\hline RPL13 & Ribosomal protein L13 (refgen) & NM_001141291 & CCAATGTACAGCGCCTGAAA & CGTGGCCATCTTGAGTTCCT & 110 & $-/ 1.91$ \\
\hline
\end{tabular}


PCR was performed using SYBR Green Master Mix (LightCycler 480 SYBR Green master mix kit, Roche Applied Sciences, Basel, Switzerland), which contains FastStart DNA polymerase, and gene-specific primers (500 nM of each). PCR was achieved with a 5 min activation and denaturizing step at $95^{\circ} \mathrm{C}$, followed by 45 cycles of a $10 \mathrm{~s}$ denaturing step at $95^{\circ} \mathrm{C}$, a $20 \mathrm{~s}$ annealing step at $60^{\circ} \mathrm{C}$ and a $30 \mathrm{~s}$ synthesis step at $72^{\circ} \mathrm{C}$. Target gene mean normalized expression (MNE) was determined using a normalization factor based upon $\mathrm{ACTB}$ and $\mathrm{EEF} 1 \mathrm{AB}$ for the temperature exposure data and $\mathrm{ACTB}, \mathrm{EF} 1 \mathrm{AB}$ and RPL13 for the low oxygen exposure data, as calculated by the geNorm software [66]. All these transcripts were stably expressed among the 30 evaluated samples, with geNorm stability scores of $\mathrm{M}<0.28$.

\section{Statistics}

Significant differences among treatments were assessed with t-test, 1-way analysis of variance (ANOVA) (temperature stress experiment) or 2-way ANOVA (low $\mathrm{O}_{2}$ experiment). Post hoc testing of significant differences was assessed by using the Tukey's HSD test. T-test was used to search for hypoxia effects from the low oxygen experiment by combining data from the high-energy and low-energy feed groups. In case of significantly different standard deviations as determined by the Bartlett's test, the data was $\log$ transformed before ANOVA analysis. Outliers were detected by using the ROUT method [67]. The GraphPad Prism 5.0 software (GraphPad Software, Inc., San Diego, CA, USA) was used for statistical analyses of the transcriptional data. Correlation analysis was performed using the program Statistica 8.0,(Statsoft Inc., Tulsa, USA). Contigs and isotigs were annotated with the Blast2GO software. The functional pathway analyses were generated through the use of IPA (Ingenuity Systems, www. ingenuity.com). A significance level of $\mathrm{P}<0.05$ was used for all tests.

\section{Availability of supporting data}

All supporting data are included as additional files.

\section{Additional files}

Additional file 1: Gene transcripts up- (worksheet A) and downregulated (worksheet $B$ ) by temperature treatment in liver of Atlantic salmon. Based on data obtained from two SSH cDNA libraries and sorted by the number of reads. Only contigs consisting of 50 or more reads were included in IPA pathway analysis.

Additional file 2: Most abundant gene transcripts in liver of Atlantic salmon A) kept at normal oxygen saturation level or B) exposed to low oxygen saturation stress. Based on data obtained from two normalized cDNA libraries and sorted by contig length. Only contigs consisting of 50 or more reads were included in IPA pathway analysis.

Additional file 3: A) Enriched gene ontologies (GOs) in liver of Atlantic salmon exposed to $19^{\circ} \mathrm{C}$. B) Enriched GOs in liver of Atlantic salmon exposed to low oxygen saturation stress ( $>50$ reads), $C$ ) Enriched GOs in liver of Atlantic salmon exposed to low oxygen levels (all reads). Duplicates were removed. GO enrichment analysis was conducted by using the Fisher's Exact Test as implemented in the Blast2GO software. $\mathrm{P}<0.05$

Additional file 4: Possible upstream regulators in liver of Atlantic salmon exposed to temperature stress as suggested by IPA analysis.

Additional file 5: Correlation analysis of evaluated transcripts in liver of Atlantic salmon exposed to A) temperature stress and B) low oxygen saturation stress.

Additional file 6: Fasta sequences of assembled contigs consisting of more than 50 reads from the four CDNA libraries.

\section{Competing interests}

The authors declare that they have no competing interests.

\section{Authors' contributions}

$\mathrm{EMH}$ and PAO initiated the study. EMH designed the two exposure experiments, and provided background information from the previously conducted trials. PAO conducted the transcriptomic work, including all the statistical analyses, and wrote the manuscript. W was involved in the low oxygen study. EMH contributed with the RT-qPCR analyses. KKL helped with the analytical work. All authors have read and approved the final manuscript.

\section{Acknowledgment}

The authors would like to thank Hui-shan Tung (NIFES) for excellent technical help with the SSH cDNA libraries. Jaap Wessels and Eva Mykkeltvedt (NIFES) for help during fish sampling and GPCR analysis. We would also like to thank Morten Skage and Ave Tooming-Klunderud (NCS, CEES, University of Oslo) for help and advise with 454 FLX sequencing. This project was financed by NIFES.

\section{Author details}

1National Institute of Nutrition and Seafood Research, Nordnesboder 1-2, N-5005 Bergen, Norway. ${ }^{2}$ Skretting Aquaculture Research Center, P.O. Box 48N-4001, Stavanger, Norway.

Received: 22 May 2013 Accepted: 14 November 2013 Published: 22 November 2013

\section{References}

1. Imsland AK, Folkvord A, Stefansson SO: Growth, oxygen consumption and activity of juvenile turbot (Scophthalmus maximus $\mathrm{L}$ ) reared under different temperatures and photoperiods. Netherlands J Sea Res 1995, 34:149-159.

2. Quinn NL, McGowan CR, Cooper GA, Koop BF, Davidson WS: Identification of genes associated with heat tolerance in Arctic charr exposed to acute thermal stress. Physiol Genomics 2011, 43:685-696.

3. Liu SK, Wang XL, Sun FY, Zhang JR, Feng JB, Liu H, Rajendran KV, Sun LY, Zhang Y, Jiang YL, Peatman E, Kaltenboeck L, Kucuktas H, Liu ZJ: RNA-Seq reveals expression signatures of genes involved in oxygen transport, protein synthesis, folding, and degradation in response to heat stress in catfish. Physiol Genomics 2013, 45(12):462-476.

4. Somero GN: Adaptation of enzymes to temperature: searching for basic "strategies". Comp Biochem Physiol B-Biochem Mol Biol 2004, 139:321-333.

5. Somero GN: The physiology of climate change: how potentials for acclimatization and genetic adaptation will determine 'winners' and 'losers'. J Exp Biol 2010, 213:912-920.

6. Hevrøy EM, Waagbo R, Torstensen BE, Takle H, Stubhaug I, Jorgensen SM, Torgersen T, Tvenning L, Susort S, Breck O, Hansen T: Ghrelin is involved in voluntary anorexia in Atlantic salmon raised at elevated sea temperatures. Gen Comp Endocrinol 2012, 175:118-134.

7. Quinn NL, McGowan CR, Cooper GA, Koop BF, Davidson WS: Ribosomal genes and heat shock proteins as putative markers for chronic, sublethal heat stress in Arctic charr: applications for aquaculture and wild fish. Physiol Genomics 2011, 43:1056-1064.

8. Evans TG, Hammill E, Kaukinen K, Schulze AD, Patterson DA, English KK, Curtis JMR, Miller KM: Transcriptomics of environmental acclimatization 
and survival in wild adult Pacific sockeye salmon (Oncorhynchus nerka) during spawning migration. Mol Ecol 2011, 20:4472-4489.

9. Kassahn KS, Caley MJ, Ward AC, Connolly AR, Stone G, Crozier RH: Heterologous microarray experiments used to identify the early gene response to heat stress in a coral reef fish. Mol Ecol 2007, 16:1749-1763.

10. Healy TM, Tymchuk WE, Osborne EJ, Schulte PM: Heat shock response of killifish (Fundulus heteroclitus): candidate gene and heterologous microarray approaches. Physiol Genomics 2010, 41:171-184

11. Logan CA, Somero GN: Effects of thermal acclimation on transcriptional responses to acute heat stress in the eurythermal fish Gillichthys mirabilis (Cooper). Am J Physiol-Regul Integr Comp Physiol 2011, 300:R1373-R1383.

12. Thorne MAS, Burns G, Fraser KPP, Hillyard G, Clark MS: Transcription profiling of acute temperature stress in the Antarctic plunderfish Harpagifer antarcticus. Mar Genomics 2010, 3:35-44.

13. Windisch HS, Kathover R, Portner HO, Frickenhaus S, Lucassen M: Thermal acclimation in Antarctic fish: transcriptomic profiling of metabolic pathways. Am J Physiol-Regul Integr Comp Physiol 2011, 301:R1453-R1466.

14. Gracey AY, Fraser EJ, Li W, Fang Y, Taylor RR, Rogers J, Brass A, Cossins AR: Coping with cold: An integrative, multitissue analysis of the transcriptome of a poikilothermic vertebrate. Proc Natl Acad Sci U S A 2004, 101:16970-16975.

15. Chou MY, Hsiao CD, Chen SC, Chen IW, Liu ST, Hwang PP: Effects of hypothermia on gene expression in zebrafish gills: upregulation in differentiation and function of ionocytes as compensatory responses. J Exp Biol 2008, 211:3077-3084.

16. Vergauwen $L$, Benoot $D$, Blust $R$, Knapen D: Long-term warm or cold acclimation elicits a specific transcriptional response and affects energy metabolism in zebrafish. Comp Biochem Physiol A-Mol Integr Physiol 2010, 157:149-157.

17. Richards JG: Physiological, behavioral and biochemical adaptations of intertidal fishes to hypoxia. J Exp Biol 2011, 214:191-199.

18. Diaz RJ, Breitburg DL: The hypoxic environment. In Fish Physiology, volume 27, Hypoxia. Edited by Richards JG, Farrell AP, Brauner CJ. Amsterdam: Elsevier; 2009:1-23.

19. Davis JC: Minimal dissolved oxygen requirements of aquatic life with emphasis on Canadian species: a review. J Fish Res Board Can 1975, 32:2295-2332

20. Gracey AY, Troll JV, Somero GN: Hypoxia-induced gene expression profiling in the euryoxic fish Gillichthys mirabilis. Proc Natl Acad Sci U S A 2001, 98:1993-1998.

21. Ton C, Stamatiou D, Liew CC: Gene expression profile of zebrafish exposed to hypoxia during development. Physiol Genomics 2003, 13:97-106.

22. van der Meer DL, van den Thillart GE, Witte F, de Bakker MA, Besser J, Richardson MK, Spaink HP, Leito JT, Bagowski CP: Gene expression profiling of the long-term adaptive response to hypoxia in the gills of adult zebrafish. Am J Physiol Regul Integr Comp Physiol 2005, 289:R1512-1519.

23. Ju ZL, Wells MC, Heater SJ, Walter RB: Multiple tissue gene expression analyses in Japanese medaka (Oryzias latipes) exposed to hypoxia. Comp Biochem Physiol C-Toxicol Pharmacol 2007, 145:134-144.

24. Zhang ZP, Ju ZL, Wells MC, Walter RB: Genomic approaches in the identification of hypoxia biomarkers in model fish species. J Exp Mar Biol Ecol 2009, 381:S180-S187.

25. Boswell MG, Wells MC, Kirk LM, Ju ZL, Zhang ZP, Booth RE, Walter RB: Comparison of gene expression responses to hypoxia in viviparous (Xiphophorus) and oviparous (Oryzias) fishes using a medaka microarray. Comp Biochem Physiol C-Toxicol Pharmacol 2009, 149:258-265.

26. Zhang ZP, Wells MC, Boswell MG, Beldorth I, Kirk LM, Wang YL, Wang SL, Savage M, Walter RB, Booth RE: Identification of robust hypoxia biomarker candidates from fin of medaka (Oryzias latipes). Comp Biochem Physiol C-Toxicol Pharmacol 2012, 155:11-17.

27. Martinovic D, Villeneuve DL, Kahl MD, Blake LS, Brodin JD, Ankley GT: Hypoxia alters gene expression in the gonads of zebrafish (Danio rerio). Aquat Toxicol 2009, 95:258-272.

28. Portner HO: Oxygen- and capacity-limitation of thermal tolerance: a matrix for integrating climate-related stressor effects in marine ecosystems. J Exp Biol 2010, 213:881-893.

29. Nikinmaa M: Climate change and ocean acidification-interactions with aquatic toxicology. Aquat Toxicol 2013, 126:365-372

30. Hevroy EM, Hunskar C, de Gelder S, Shimizu M, Waagbo R, Breck O, Takle H, Sussort S, Hansen T: GH-IGF system regulation of attenuated muscle growth and lipolysis in Atlantic salmon reared at elevated sea temperatures. J Comp Physiol B-Biochem Syst Environ Physiol 2013, 183:243-259.

31. Oliveros JC: VENNY. An interactive tool for comparing lists with Venn Diagrams; 2007. http://bioinfogp.cnb.csic.es/tools/venny/index.html.

32. Wang T, Lefevre S, Huong DTT, Cong NV, Bayley M: The effects of hypoxia on growth and digestion. In Fish Physiology, volume 27, Hypoxia. Edited by Richards JG, Farrell AP, Brauner CJ. Amsterdam: Elsevier; 2009:361-396.

33. Boutilier RG: Mechanisms of cell survival in hypoxia and hypothermia. J Exp Biol 2001, 204:3171-3181.

34. Breitburg D: Effects of hypoxia, and the balance between hypoxia and enrichment, on coastal fishes and fisheries. Estuar Coast Shelf Sci 2002, 25:767-781

35. Burt K, Hamoutene D, Mabrouk G, Lang C, Puestow T, Drover D, Losier R, Page F: Environmental conditions and occurrence of hypoxia within production cages of Atlantic salmon on the south coast of Newfoundland. Aquacult Res 2012, 43:607-620.

36. Schreck CB: Stress and fish reproduction: The roles of allostasis and hormesis. Gen Comp Endocrinol 2010, 165(3):549-556.

37. Heise K, Puntarulo S, Nikinmaa M, Abele D, Portner HO: Oxidative stress during stressful heat exposure and recovery in the North Sea eelpout Zoarces viviparus L. J Exp Bio/ 2006, 209:353-363.

38. GeneCards database. http://www.genecards.org

39. Olsvik PA, Kristensen T, Waagbo R, Tollefsen KE, Rosseland BO, Toften H: Effects of hypo- and hyperoxia on transcription levels of five stress genes and the glutathione system in liver of Atlantic cod Gadus morhua. J Exp Biol 2006, 209:2893-2901.

40. Hites RA, Foran JA, Carpenter DO, Hamilton MC, Knuth BA, Schwager SJ: Global assessment of organic contaminants in farmed salmon. Science 2004, 303:226-229.

41. Sleiderink HM, Beyer J, Everaarts JM, Boon JP: Influence of temperature on cytochrome-P450 1a in dab (Limanda limanda) from the southern North-Sea - Results from field surveys and a laboratory study. Mar Environ Res 1995, 39:67-71.

42. Lyons MC, Wong DKH, Mulder I, Lee K, Burridge LE: The influence of water temperature on induced liver EROD activity in Atlantic cod (Gadus morhua) exposed to crude oil and oil dispersants. Ecotoxicol Environ Safety 2011, 74:904-910.

43. Rebl A, Verleih M, Kobis JM, Kuhn C, Wimmers K, Kollner B, Goldammer T: Transcriptome profiling of gill tissue in regionally bred and globally farmed rainbow trout strains reveals different strategies for coping with thermal stress. Mar Biotechnol (NY) 2013, 15:445-460.

44. Wu RSS: Effects of hypoxia on fish reproduction and development. In Fish Physiology, volume 27, Hypoxia. Edited by Richards JG, Farrell AP, Brauner CJ. Amsterdam: Elsevier; 2009:79-141.

45. Rahman MS, Thomas P: Effects of hypoxia exposure on hepatic cytochrome P450 1A (CYP1A) expression in Atlantic croaker: Molecular mechanisms of CYP1A down-regulation. Plos One 2012, 7(7):e40825. doi:10.1371/journal.pone.0040825.

46. Leveelahti L, Leskinen P, Leder EH, Waser W, Nikinmaa M: Responses of threespine stickleback (Gasterosteus aculeatus, L) transcriptome to hypoxia. Comp Biochem Physiol D-Genomics Proteomics 2011, 6:370-381.

47. Richards JG: Metabolic and molecular responses to hypoxia. In Fish Physiology, volume 27, Hypoxia. Edited by Richards JG, Farrell AP, Brauner CJ. Amsterdam: Elsevier; 2009:443-485.

48. Storey KB, Storey JM: Metabolic rate depression in animals: transcriptional and translational controls. Biol Rev 2004, 79:207-233.

49. Jibb LA, Richards JG: AMP-activated protein kinase activity during metabolic rate depression in the hypoxic goldfish, Carassius auratus. J Exp Biol 2008, 211:3111-3122.

50. Wenger $\mathrm{RH}$ : Cellular adaptation to hypoxia: O2-sensing protein hydroxylases, hypoxia-inducible transcription factors, and O2-regulated gene expression. FASEB J 2002, 16:1151-1162.

51. Terova G, Rimoldi S, Cora S, Bernardini G, Gornati R, Saroglia M: Acute and chronic hypoxia affects HIF-1 alpha mRNA levels in sea bass (Dicentrarchus labrax). Aquaculture 2008, 279:150-159.

52. Rissanen E, Tranberg HK, Sollid J, Nilsson GE, Nikinmaa M: Temperature regulates hypoxia-inducible factor-1 (HIF-1) in a poikilothermic vertebrate, crucian carp (Carassius carassius). J Exp Biol 2006, 209:994-1003.

53. Rahman MS, Thomas P: Characterization of three IGFBP mRNAs in Atlantic croaker and their regulation during hypoxic stress: potential 
mechanisms of their upregulation by hypoxia. Am J Physiol-Endocrinol Metabol 2011, 301:E637-E648.

54. Kajimura S, Aida K, Duan CM: Insulin-like growth factor-binding protein-1 (IGFBP-1) mediates hypoxia-induced embryonic growth and developmental retardation. Proc Natl Acad Sci U S A 2005, 102:1240-1245.

55. Kajimura S, Aida K, Duan CM: Understanding hypoxia-induced gene expression in early development: In vitro and in vivo analysis of hypoxia-inducible factor 1-regulated zebra fish insulin-like growth factor binding protein 1 gene expression. Mol Cell Biol 2006, 26:1142-1155.

56. Allendorf FW, Thorgaard GH: Tetraploidy and the evolution of salmonid fishes. In Evolutionary Genetics of Fishes. Edited by Turner BJ. New York: Plenum Press; 1984:1-53.

57. Kamei H, Lu L, Jiao S, Li Y, Gyrup C, Laursen LS, Oxvig C, Zhou JF, Duan CM: Duplication and diversification of the hypoxia-inducible IGFBP-1 gene in zebrafish. Plos One 2008, 3(8):e3091. doi:10.1371/journal.pone.0003091.

58. Vandernoot VA, Langevin SA, Solberg OD, Lane PD, Curtis DJ, Bent ZW, Williams KP, Patel KD, Schoeniger JS, Branda SS, Lane TW: CDNA normalization by hydroxyapatite chromatography to enrich transcriptome diversity in RNA-seq applications. Biotechniques 2012, 53:373-380.

59. Rytkonen KT, Akbarzadeh A, Miandare HK, Kamei H, Duan CM, Leder EH, Williams TA, Nikinmaa M: Subfunctionalization of cyprinid hypoxia-inducible factors for roles in development and oxygen sensing. Evolution 2013, 67:873-882.

60. Remen M, Oppedal F, Torgersen T, Imsland AK, Olsen RE: Effects of cyclic environmental hypoxia on physiology and feed intake of post-smolt Atlantic salmon: initial responses and acclimation. Aquaculture 2012, 326:148-155.

61. Huson DH, Auch AF, Qi J, Schuster SC: MEGAN analysis of metagenomic data. Genome Res 2007, 17:377-386.

62. Altschul SF, Gish W, Miller W, Myers EW, Lipman DJ: Basic Local Alignment Search Tool. J Mol Biol 1990, 215:403-410.

63. Conesa A, Gotz S, Garcia-Gomez JM, Terol J, Talon M, Robles M: Blast2GO: a universal tool for annotation, visualization and analysis in functional genomics research. Bioinformatics 2005, 21:3674-3676.

64. Bluthgen N, Brand K, Cajavec B, Swat M, Herzel H, Beule D: Biological profiling of gene groups utilizing Gene Ontology. Genome Inform 2005, 16:106-115

65. Olsvik PA, Lie KK, Nordtug T, Hansen BH: Is chemically dispersed oil more toxic to Atlantic cod (Gadus morhua) larvae than mechanically dispersed oil? A transcriptional evaluation. BMC Genomics 2012, 13:702.

66. Vandesompele J, De Preter K, Pattyn F, Poppe B, Van Roy N, De Paepe A Speleman F: Accurate normalization of real-time quantitative RT-PCR data by geometric averaging of multiple internal control genes. Genome Biol 2002, 3(7). research0034.1 -research0034.11.

67. Motulsky HJ, Brown RE: Detecting outliers when fitting data with nonlinear regression - a new method based on robust nonlinear regression and the false discovery rate. BMC Bioinformatics 2006, 7:123.

doi:10.1186/1471-2164-14-817

Cite this article as: Olsvik et al:: Transcriptional responses to temperature and low oxygen stress in Atlantic salmon studied with next-generation sequencing technology. BMC Genomics 2013 14:817.

\section{Submit your next manuscript to BioMed Central and take full advantage of:}

- Convenient online submission

- Thorough peer review

- No space constraints or color figure charges

- Immediate publication on acceptance

- Inclusion in PubMed, CAS, Scopus and Google Scholar

- Research which is freely available for redistribution

Submit your manuscript at www.biomedcentral.com/submit
Ciomed Central 